\title{
Innovation, Productivity, and Monetary Policy
}

Moran, Patrick and Albert Queralto

Please cite paper as:

Moran, Patrick and Albert Queralto (2017). Innovation,

Productivity, and Monetary Policy. International Finance

Discussion Papers 1217.

\section{https://doi.org/10.17016/IFDP.2017.1217}

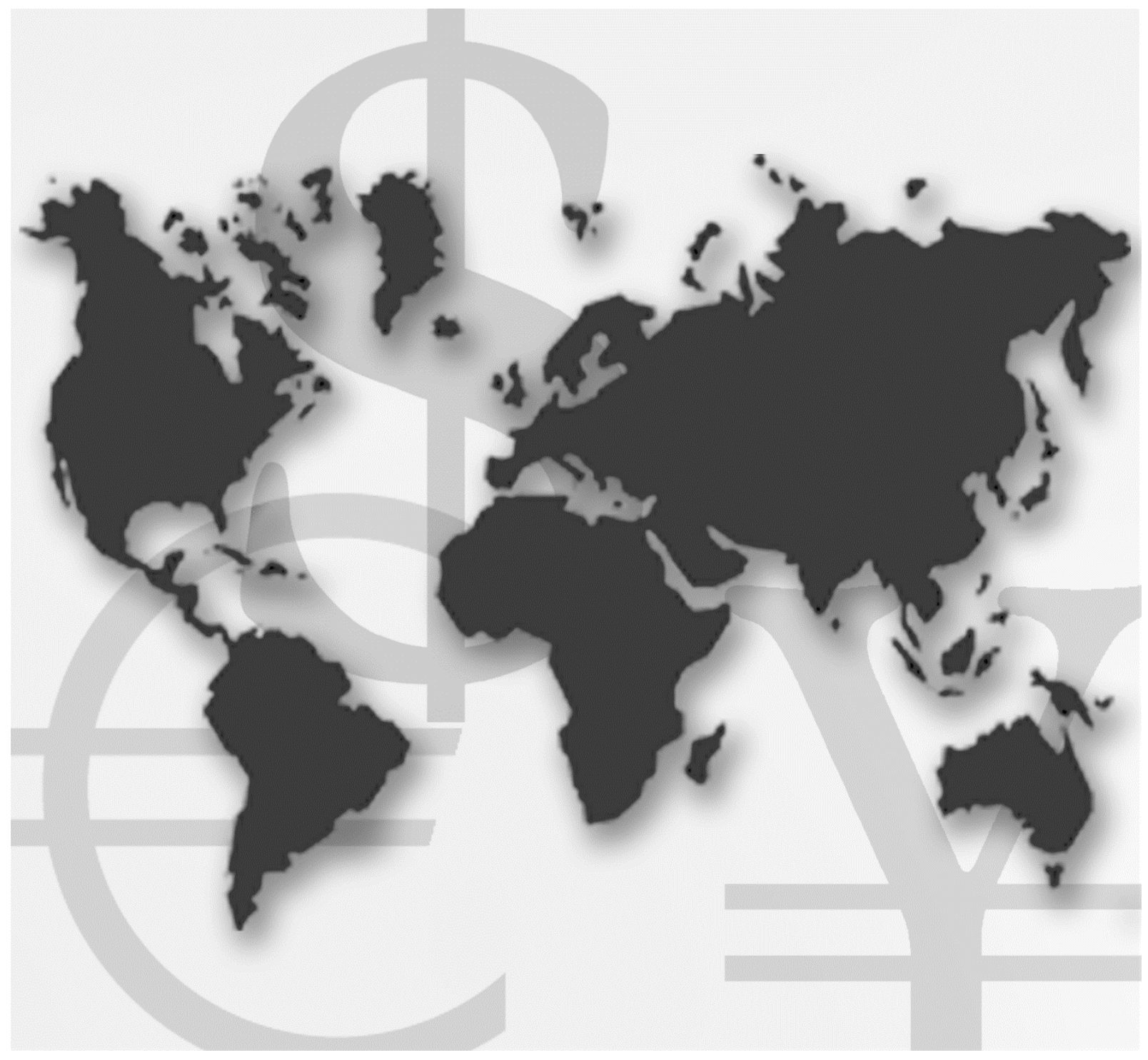

\section{International Finance Discussion Papers}

Board of Governors of the Federal Reserve System

Number 1217

November 2017 
Board of Governors of the Federal Reserve System

International Finance Discussion Papers

Number 1217

November 2017

\title{
Innovation, Productivity, and Monetary Policy
}

\author{
Patrick Moran and Albert Queralto
}

NOTE: International Finance Discussion Papers are preliminary materials circulated to stimulate discussion and critical comment. References in publications to International Finance Discussion Papers (other than an acknowledgment that the writer has had access to unpublished material) should be cleared with the author or authors. Recent IFDPs are available on the Web at https://www.federalreserve.gov/econres/ifdp/. This paper can be downloaded without charge from Social Science Research Network electronic library at http://www.sssrn.com. 


\title{
Innovation, Productivity, and Monetary Policy*
}

\author{
Patrick Moran ${ }^{\dagger}$ \\ University of Oxford
}

\author{
Albert Queralto $\ddagger$ \\ Federal Reserve Board
}

November 21, 2017

\begin{abstract}
To what extent can monetary policy impact business innovation and productivity growth? We use a New Keynesian model with endogenous total factor productivity (TFP) to quantify the TFP losses due to the constraints on monetary policy imposed by the zero lower bound (ZLB) and the TFP benefits of tightening monetary policy more slowly than currently anticipated. In the model, monetary policy influences firms incentives to develop and implement innovations. We use evidence on the dynamic effects of R\&D and monetary shocks to estimate key parameters and assess model performance. The model suggests significant TFP losses due to the ZLB.
\end{abstract}

Keywords: Endogenous Technology; Business Cycles; Monetary Policy.

JEL classification: E32; F41; F44; G15.

\footnotetext{
* This paper was prepared for the Carnegie-Rochester Conference Series on Public Policy. We thank the Editor, Narayana Kocherlakota, and an anonymous referee for very helpful comments that greatly improved the paper. We also thank our discussant, Michael Waugh, for very insightful comments, as well as seminar participants at the April 2017 Carnegie-RochesterNYU Conference, the Federal Reserve Board, Yale University, the 2017 meeting of the Catalan Economic Society, and the 2017 meeting of the International Economic Association for comments. The views expressed in this paper are solely the responsibility of the authors, and should not be interpreted as reflecting the views of the Board of Governors of the Federal Reserve System or of any other person associated with the Federal Reserve System.

${ }^{\dagger}$ Department of Economics, Manor Road Building, Oxford OX1 3UQ, UK. Email: patrick.donnellymoran@economics.ox.ac.uk

${ }^{\ddagger}$ Corresponding author. Federal Reserve Board, 20th St and Constitution Ave NW, Washington, DC, 20551, USA. Email: albert.queralto@frb.gov.
} 


\section{Introduction}

Growth in total factor productivity (TFP) has slowed dramatically in recent years: as seen in Figure 1, U.S. TFP growth in the post-1980s has never been as low for as long as during the post-2007 period. ${ }^{1}$ This development has been a cause of widespread concern, and at the same time has sparked an intense debate on its possible causes, with the role of innovation and business dynamism the subject of increasing attention. ${ }^{2}$ From the vantage of monetary policymakers, an important open question is to what extent can monetary policy exert influence on TFP.

Figure 1: U.S. TFP Growth

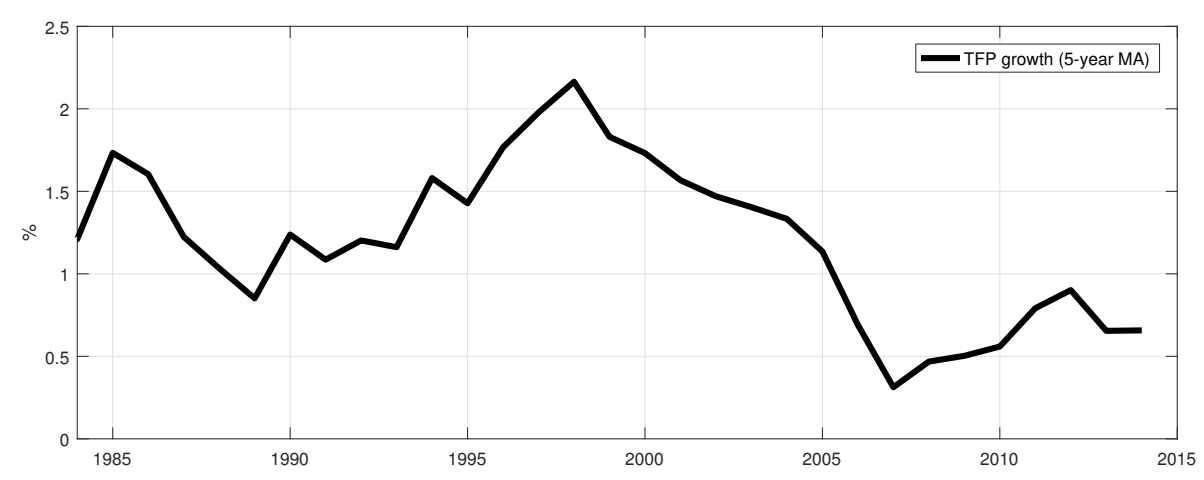

Note: 5-year moving average (two-sided) of annual U.S. TFP growth.

This paper analyzes the link between monetary policy and TFP dynamics using a New Keynesian model that endogenizes TFP. In the model, technology innovation and adoption drive medium-run swings in TFP. ${ }^{3}$ We begin by illustrating how monetary policy in the model works to induce medium-run movements in TFP, through its impact on firms' incentives to develop innovations and implement them in production. We then use the model to address two specific questions. First, we ask to what extent the zero lower bound (ZLB) constraint on monetary policy played a role in driving the weakness in TFP growth seen since the onset

\footnotetext{
${ }^{1}$ The slowdown has been widespread across advanced economies. See, for instance, the July 2017 Monetary Policy Report to Congress, p. 12-13.

${ }^{2}$ For example, Yellen (2016a) emphasizes that "[...] understanding whether, and by how much, productivity growth will pick up is a crucial part of the economic outlook" and notes that "there is some evidence that the deep recession had a long-lasting effect in depressing investment, research and development spending, and the start-up of new firms, and that these factors have, in turn, lowered productivity growth."

${ }^{3} \mathrm{~A}$ recent but growing literature in macroeconomics incorporates endogenous TFP mechanisms of this type within modern quantitative frameworks, following the lead of Comin and Gertler (2006). See, for example, Anzoategui, Comin, Gertler and Martinez (2017), Benigno and Fornaro (2016), Bianchi et al. (2014), GuerronQuintana and Jinnai (2014), Kung and Schmid (2015), or Queralto (2013).
} 
of the Great Recession. Second, we examine how much future monetary policy can influence future TFP, by tightening more slowly than currently projected.

Our findings suggest, first, that the adverse impact of the ZLB on TFP was substantial. In particular, the constraints imposed by the lower bound on monetary policy from 2009 to 2015 led the levels of TFP and output to be permanently lower by 1.75 percent and 2.5 percent, respectively. Thus, according to our model, the ZLB accounts for a significant fraction of the TFP and output shortfall relative to pre-crisis projections. Second, we find that slower tightening of monetary policy after 2016 may significantly enhance longer-run TFP and output. In particular, an alternative path for the policy rate which reaches the long-run level of 3 percent around 2025 (rather than in 2019 as under current projections) results in a boost in long-run TFP of 1 percent, and in long-run GDP of 1.5 percent.

An important aspect of our analysis is the use of identified vector autoregressions (VARs) to obtain estimates of the dynamic effects of innovation (as measured by aggregate private R\&D expenditure) on TFP dynamics. These estimates indicate that increases in R\&D in the data tend to induce gradual, persistent increases in TFP, consistent with the model's predictions. The VAR evidence then proves useful to identify key model parameters linking innovation and TFP. In addition, our analysis also employs identified VARs as a check on the model's empirical plausibility. We do this in two ways. First, we document the dynamic effects of R\&D in a larger-scale VAR (including a set of standard macroeconomic variables) and compare them against the model's predictions. Second, we examine the dynamic effects of monetary policy in a VAR which, in addition to standard macroeconomic variables, includes both R\&D spending and TFP, and also compare the resulting estimates against the model's predicted effects of monetary policy shocks. Here, VAR-based estimates of the effects of monetary policy shocks point to a rise in both R\&D and in medium-run TFP following an expansionary monetary shock, consistent with the model. Overall, the model does reasonably well on both fronts.

Among the papers cited above, the closest to ours are Bianchi et al. (2014) and Anzoategui et al. (2017), who also develop and estimate quantitative macroeconomic frameworks with nominal rigidities and endogenous TFP dynamics. Our approach to modeling innovation and adoption differs significantly from that in Bianchi et al. (2014). For example, theirs is a Schumpeterian model of vertical innovations, while we use an expanding-variety framework as in Romer (1990). In that respect, our model is much closer to the one in Anzoategui et al. (2017), in turn based on Comin and Gertler (2006). In addition to some differences in focus - our analysis is geared towards exploring the transmission from monetary policy to productivity, while both Anzoategui et al. (2017) and Bianchi et al. (2014) give more attention to explaining historical episodes - our work differs from these frameworks by making 
extensive use of VAR methods to estimate key model parameters, and to assess the model's quantitative performance. The benefit of this estimation strategy is that it allows us to focus on the endogenous productivity mechanism, does not rely upon a correct specification of other shocks, and can be used to ensure that the model fits well the dynamic effects of R\&D in the data. This approach also motivates some modeling differences - most notably, our model includes a complementarity between R\&D and technology adoption that is absent in Anzoategui et al. (2017) and Comin and Gertler (2006), which we show improves the model's ability to fit the data.

The rest of the paper is organized as follows. Section 2 describes the model. Section 3 describes the parameterization of the model and the model assessment against the VAR evidence. Section 4 contains the counterfactual experiments on the role of the ZLB and of slower tightening post-2016. Section 5 concludes.

\section{Model}

This section describes the theoretical framework, consisting of a standard medium-sized New Keynesian model augmented to include endogenous technology innovation and adoption. We begin by describing the evolution of endogenous technology in section 2.1, which constitutes the main departure from other medium-sized DSGE models found in the literature. The remaining sections then characterize each set of agents in the model.

\subsection{Evolution of technology}

We model technology following Comin and Gertler (2006), which is in turn based on the expanding-variety framework due to Romer (1990). Innovations in the model take the form of new varieties of intermediate goods, which are discovered endogenously as a result of R\&D activity by private innovators. We let the aggregate measure of existing technologies (or the "technological frontier") be denoted by the variable $Z_{t}$. Any point on the real line between 0 and $Z_{t}$ represents a distinct variety of intermediate. Each of these technologies is subject to exogenous obsolescence, which occurs with probability $1-\phi$. Let $V_{t}$ be the aggregate amount of innovations developed during period $t$. In the following subsection, describing innovators' optimization problem, we explain how $V_{t}$ is determined. The technology frontier $Z_{t}$ thus evolves as follows:

$$
Z_{t+1}=\phi Z_{t}+V_{t}
$$


New technologies, once discovered, are not yet readily available for use in production. Rather, they are incorporated into use through a process that requires both time and resources. Specifically, a competitive set of "technology adopters" spend resources each period to try to make technologies usable. Each adopter succeeds with probability $\lambda_{t}$, which is assumed to be an increasing function of the resources spent. If he is not successful, the adopter may try again in the following period. Thus, adoption generally takes multiple periods, and the adoption rate $\lambda_{t}$ may vary with economic conditions. Section 2.3 below characterizes the problem facing technology adopters.

Let the measure of technologies that are available for use be denoted $A_{t}$, satisfying $A_{t}<Z_{t}$ at all times. The variable $A_{t}$ determines aggregate TFP. As a result of the adoption process just described, the evolution of $A_{t}$ is given by the following:

$$
A_{t+1}=\phi\left[\lambda_{t}\left(Z_{t}-A_{t}\right)+A_{t}\right]
$$

Dividing the above equation by $A_{t}$ yields an equation characterizing the growth rate of TFP, which is governed by two variables: the rate of technology adoption, $\lambda_{t}$, and the stock of total technologies relative to adopted technologies, $Z_{t} / A_{t}$.

\subsection{Innovators}

Competitive innovators spend resources in $R \& D$ to develop new intermediate goods. They then sell the rights to the new goods to an adopter, who converts the idea for the new product into an employable input, as described in the next subsection.

Specifically, each innovator $i$ has access to the following production function:

$$
V_{i, t}=\zeta Z_{t} \frac{1}{Z_{t}^{\eta} S_{t}^{1-\eta}} S_{i, t}
$$

Here $V_{i, t}$ denotes new products developed by innovator $i$ and $S_{i, t}$ his R\&D expenditure (in units of final output). Aggregate $\mathrm{R} \& \mathrm{D}$ is $S_{t} \equiv \int_{i} S_{i, t} d i$. As in Romer (1990), there is a positive spillover from the aggregate stock of innovations, $Z_{t}$, to individual R\&D productivity. At the same time, the term $\frac{1}{Z_{t}^{\eta} S_{t}^{1-\eta}}$ introduces a "congestion" externality from aggregate R\&D. Motivating such an externality is the notion that the best ideas may be the ones that are first discovered. Under this formulation, in equilibrium the R\&D elasticity of aggregate technology creation is given by the parameter $\eta$, satisfying $0<\eta<1$. The congestion effect depends positively on the technological frontier $Z_{t}$, capturing the notion that as the economy becomes more sophisticated the efficiency of $R \& D$ declines. This term helps ensure that the growth rate of new intermediate products is stationary. The parameter $\zeta$ is a scaling factor that we 
calibrate so that the model delivers a realistic growth rate of TFP in the balanced growth path.

Let $J_{t}$ be the value of a new "unadopted" innovation. We describe how $J_{t}$ is determined in the following subsection. Innovations developed at $t$ become available starting in $t+1$. Accordingly, letting $\varphi_{t} \equiv \frac{\zeta Z_{t}}{Z_{t}^{\eta} S_{t}^{1-\eta}}$, innovator $i$ 's problem is

$$
\max _{\left\{S_{i, t+j}\right\}_{j=0}^{\infty}} \mathbb{E}_{t}\left\{\sum_{j=0}^{\infty} \Lambda_{t, t+1+j}\left[J_{t+1+j} \varphi_{t+j} S_{i, t+j}-\left(1+\Delta_{t}^{s}\right)\left(1+f_{s}\left(S_{i, t+j} / S_{i, t+j-1}\right)\right) S_{i, t+j}\right]\right\}
$$

Where $\Lambda_{t, t+1}$ denotes the household's stochastic discount factor between $t$ and $t+1$. The convex function $f_{s}(\cdot)$ captures costs of adjusting the level of R\&D. It satisfies $f_{s}(\bar{g})=f_{s}^{\prime}(\bar{g})=0$ where $\bar{g}$ denotes the growth rate of R\&D along the balanced growth path (which coincides with the growth rate of technology, output, and other aggregates). In addition, innovators' problem above includes an exogenous R\&D tax, or "wedge," given by the variable $\Delta_{t}^{s}$. We assume the wedge follows a first-order autoregressive process: $\Delta_{t}^{s}=\rho_{s} \Delta_{t-1}^{s}+\epsilon_{t}^{s}$. The wedge effectively introduces a gap between the marginal benefit and the marginal cost of innovation. The variable $\Delta_{t}^{s}$ plays an important role in our model estimation exercise. In particular, we use variation in the wedge to initiate movements in $\mathrm{R} \& \mathrm{D}$, and then trace out the effects on TFP and other variables. We then calculate the analogous object in the data, using a VAR to identify shocks to R\&D. We estimate key model parameters governing the innovation sector by requiring that the dynamic effects of $R \& D$ in the model match those in the data.

One possible interpretation for the wedge is that it reflects frictions in financial intermediation, constraining credit for innovators. ${ }^{4}$ More generally, we think of the wedge as a reduced-form way of inducing movements in $\mathrm{R} \& \mathrm{D}$, be it due to financing constraints or to other (unmodeled) sources of variation of the desirability of R\&D investments.

Given that all innovators make the same choices, we now drop the $i$ subindex. The firstorder condition for the problem above is given by

$\mathbb{E}_{t}\left(\Lambda_{t, t+1} J_{t+1}\right) \varphi_{t}=\left(1+\Delta_{t}^{s}\right)\left\{1+f_{s}^{\prime}\left(S_{t} / S_{t-1}\right) \frac{S_{t}}{S_{t-1}}+f_{s}\left(S_{t} / S_{t-1}\right)-\mathbb{E}_{t}\left[\Lambda_{t, t+1} f_{s}^{\prime}\left(S_{t+1} / S_{t}\right)\left(\frac{S_{t+1}}{S_{t}}\right)^{2}\right]\right\}$

\footnotetext{
${ }^{4}$ See Queralto (2013) for an explicit model of this channel. The data offers some evidence in support of the notion that financing constraints affect $R \& D$ : when we compare the orthogonalized shocks to R\&D from our VAR (identified by assuming that they do not affect TFP contemporaneously) to the excess bond premium (Gilchrist and Zakrajšek (2012)), we find a strong negative correlation between current and lagged values of the excess bond premium and the orthogonalized shocks to R\&D.
} 
Equation (5) sets the marginal benefit from R\&D to its marginal cost, including the wedge $\Delta_{t}^{s}$. The marginal benefit of R\&D includes the expected discounted value of an (unadopted) innovation tomorrow, given by $\mathbb{E}_{t}\left(\Lambda_{t, t+1} J_{t+1}\right)$. Aggregate innovation, which determines the evolution of the frontier $Z_{t}$ (see equation (1)) is then $V_{t} \equiv \int_{i} V_{i, t} d i=\zeta Z_{t}^{1-\eta} S_{t}^{\eta}$. Note that $\eta$ governs the elasticity of $V_{t}$ to $S_{t}$. This elasticity is one of the key parameters that we estimate using VAR evidence on R\&D and TFP. Using the equation for $V_{t}$ in (1) we obtain that the growth rate of $Z_{t}$ is determined by the ratio $S_{t} / Z_{t}$ (with elasticity $\eta$ ). Thus, long-run growth in the technology frontier (and therefore in TFP) is fully endogenous in our model: permanent changes in $\Delta_{t}^{s}$, for example, lead to permanent changes in the growth rate of $Z_{t}$.

\subsection{Adopters}

Competitive technology adopters employ resources to convert available technologies into use. Each adopter succeeds in making a product usable in any given period with probability $\lambda_{t}$. If the adopter is not successful in period $t$, he may try again in $t+1$. This success probability depends positively on the amount of expenditures by the adopter. Given that the success rate will be the same across products, this formulation facilitates aggregation.

As a way to introduce adjustment costs in adoption activity, we suppose that adopters' input is a specialized good (e.g. equipment) that is produced using final output by equipment producers, described below. ${ }^{5}$ The latter agents face adjustment costs that are analogous to those faced by innovators and by capital goods producers. We denote the price of the equipment good used by adopters by $Q_{t}^{m}$.

Let $M_{i, t}$ be the amount of equipment used by any adopter $i$. The probability of a successful adoption, $\lambda_{t}$, depends on $M_{i, t}$ and is given by the following:

$$
\lambda_{t}\left(M_{i, t}\right)=\kappa_{\lambda}\left(S_{t} / A_{t}\right)^{\nu} M_{i, t}^{\rho_{\lambda}}
$$

with $\kappa_{\lambda}>0,0<\nu<1$, and $0<\rho_{\lambda}<1$. The probability of a successful adoption is increasing and concave in adoption effort $M_{i, t}$. Different from Comin and Gertler (2006), we assume the probability of successful adoption includes a "spillover" from aggregate R\&D expenditure $S_{t}$ (relative to the total stock of adopted innovations $A_{t}$, which ensures that the spillover term is stationary). The idea here is that aggregate $R \& D$ may have a benign externality effect on the likelihood of adoption of existing innovations, for example because

\footnotetext{
${ }^{5}$ We have found that adjustment costs of adoption investments are necessary avoid excessive volatility in adoption activity, e.g. in response to monetary shocks.
} 
adopters learn from aggregate R\&D efforts. ${ }^{6}$ In addition to having some plausibility, this spillover term is critical for the model to be able to generate realistic TFP dynamics following an innovation shock, as we illustrate in detail below. The parameter $\nu$-governing the strength of the spillover - is another of the key parameters that we estimate.

An adopter $i$ buys the rights to an unadopted technology from innovators, at competitive price $J_{t}$. The adopter then uses resources $M_{i, t}$ which lead to the technology becoming usable for production with probability $\lambda_{t}\left(M_{i, t}\right)$. If the adopter is successful, he sells the adopted technology to goods producers obtaining for it the price $H_{t}$, given by

$$
H_{t}=\Pi_{t}+\phi \mathbb{E}_{t}\left(\Lambda_{t, t+1} H_{t+1}\right)
$$

where $\Pi_{t}$ is the monopoly profit from operating the technology.

The problem of an adopter is

$$
J_{t}=\max _{M_{i, t}}-Q_{t}^{m} M_{i, t}+\phi \mathbb{E}_{t}\left\{\Lambda_{t, t+1}\left[\lambda_{t}\left(M_{i, t}\right) H_{t+1}+\left(1-\lambda_{t}\left(M_{i, t}\right)\right) J_{t+1}\right]\right\}
$$

Since $M_{i, t}$ is the same across adopters, we omit the $i$ subscript in what follows. Adopters' first-order condition is given by

$$
\rho_{\lambda} \kappa_{\lambda} \phi\left(S_{t} / A_{t}\right)^{\nu} \mathbb{E}_{t}\left[\Lambda_{t, t+1}\left(H_{t+1}-J_{t+1}\right)\right]=Q_{t}^{m} M_{t}^{1-\rho_{\lambda}}
$$

Adoption effort $M_{t}$ is increasing in the expected discounted value of the difference $H_{t}-J_{t}$, i.e. in the difference in value between an adopted and an unadopted technology. In addition, everything else equal, increases in aggregate $R \& D$ will also lead to increases in adoption effort (via the externality term in (6)), as aggregate R\&D enhances the marginal benefit of adoption expenditure $M_{t}$. Thus, the R\&D externality in (6) works to introduce complementarity between R\&D and technology adoption - a feature that is clearly favored by the data, as we show below.

In period $t$ there is a measure $Z_{t}-A_{t}$ of technologies which adopters are attempting to convert into use, with each adopter using $M_{t}$ equipment goods. Accordingly, the aggregate amount of goods used by adopters is given by $\left(Z_{t}-A_{t}\right) M_{t}$.

\footnotetext{
${ }^{6}$ Griffith et al. (2004), for instance, emphasize that an important role of R\&D is to facilitate the adoption of existing innovations.
} 


\subsection{Intermediate goods producers}

Each of the $A_{t}$ varieties of intermediates that are actively used as of period $t$ is produced by a monopolistically competitive producer. Wholesale output, $Y_{t}^{w}$, is a CES aggregate of individual intermediate goods:

$$
Y_{t}^{w}=\left[\int_{0}^{A_{t}} Y_{i, t}^{m \frac{\vartheta-1}{\vartheta}} d i\right]^{\frac{\vartheta}{\vartheta-1}}
$$

Wholesale output is then used to produce final output by retailers, described below, who are subject to nominal rigidities. In (10), $Y_{i, t}^{m}$ is output by the producer of intermediate $i$. Each intermediates producer sets (nominal) price $P_{i, t}$. The price level of wholesale output associated with $(10)$ is then $P_{t}^{w}=\left[\int_{0}^{A_{t}} P_{i, t}^{1-\vartheta} d i\right]^{\frac{1}{1-\vartheta}}$. Each intermediate goods producer $i$ combines capital $K_{i, t}$ and labor $L_{i, t}$ to produce their variety, using a Cobb-Douglas production function:

$$
Y_{i, t}^{m}=K_{i, t}^{\alpha} L_{i, t}^{1-\alpha}
$$

Solving the intermediate good firm's problem yields standard first order conditions for pricing, labor, and capital. Let $W_{t}$ be the nominal wage and $R_{t}^{k}$ the real rental rate of capital. Cost minimization by intermediates producers yields the following conditions

$$
\begin{aligned}
W_{t} / P_{t} & =\frac{1}{\mathcal{M}_{\vartheta}} \frac{1}{\mathcal{M}_{t}}(1-\alpha) \frac{Y_{t}^{w}}{L_{t}} \\
R_{t}^{k} & =\frac{1}{\mathcal{M}_{\vartheta}} \frac{1}{\mathcal{M}_{t}} \alpha \frac{Y_{t}^{w}}{K_{t}}
\end{aligned}
$$

Here, $\mathcal{M}_{\vartheta} \equiv \vartheta /(\vartheta-1)$ is the markup arising from imperfect competition in intermediates production, and $\mathcal{M}_{t}$ is the markup of the final output price level, $P_{t}$, over the wholesale output price level: $\mathcal{M}_{t} \equiv \frac{P_{t}}{P_{t}^{w}}$. The determination of $P_{t}$ is described in subsection 2.5 characterizing retailers.

Real per-period profits by intermediates producers, denoted $\Pi_{t}$, are equal across firms and can be shown to be given by

$$
\Pi_{t}=\frac{1}{\vartheta} \frac{1}{\mathcal{M}_{t}} \frac{Y_{t}^{w}}{A_{t}}
$$

The present discounted value of the profit flow (14) constitutes the main driver of technology adoption and ultimately of innovation, as suggested by equations (9) and (5).

Combining (10) with the first-order conditions for intermediates producers and with equi- 
librium in factor markets yields the following expression for aggregate wholesale output $Y_{t}^{w}$ :

$$
Y_{t}^{w}=A_{t}^{\frac{1}{\vartheta-1}} K_{t}^{\alpha} L_{t}^{1-\alpha}
$$

Here $K_{t}$ and $L_{t}$ denote aggregate capital and labor: $K_{t} \equiv \int_{0}^{A_{t}} K_{i, t} d i, L_{t} \equiv \int_{0}^{A_{t}} L_{i, t} d i$. Equation (15) makes clear that TFP is driven by the measure of adopted varieties of intermediates, $A_{t}$.

\subsection{Retailers}

A continuum of mass unity of retail firms produce final output using wholesale output as input. Each producer simply purchases wholesale output, costlessly differentiates it, and sells it to final output users. Final output $Y_{t}$ is a CES composite of retailers' output:

$$
Y_{t}=\left[\int_{0}^{1} Y_{i, t}^{r} \frac{\omega-1}{\omega} d i\right]^{\frac{\omega}{\omega-1}}
$$

where $Y_{i, t}^{r}$ is output by retailer $i \in[0,1]$. Let the price set by retailer $i$ be $P_{i, t}$. The final output price level is $P_{t}=\left[\int_{0}^{1} P_{i, t}^{1-\omega} d i\right]^{\frac{1}{1-\omega}}$. Cost minimization by users of final output yields a standard demand function for retailer $i$ 's output:

$$
Y_{i, t}^{r}=\left(\frac{P_{i, t}}{P_{t}}\right)^{-\omega} Y_{t}
$$

Each retailer can only reset its price with probability $1-\theta$. Firms not resetting their price follow the indexation rule

$$
P_{i, t}=P_{i, t-1} \pi_{t-1}^{\iota_{p}} \bar{\pi}^{1-\iota_{p}}
$$

where $\pi_{t} \equiv P_{t} / P_{t-1}$ is inflation and $\bar{\pi}$ its steady state. Nominal marginal cost for retailers is $P_{t}^{w}$. The problem facing a retailer resetting its price in period $t$ is

$$
\max _{P_{t}^{*}} \mathbb{E}_{t} \sum_{j=0}^{\infty} \theta^{i} \Lambda_{t, t+j}\left(\frac{P_{t}^{*} \prod_{k=1}^{j} \pi_{t+k-1}^{\iota_{p}} \bar{\pi}^{1-\iota_{p}}}{P_{t+j}}-\frac{P_{t+j}^{w}}{P_{t+j}}\right) Y_{i, t+j}^{r}
$$

subject to the demand function (17). 


\subsection{Capital and equipment producers}

Capital producers make new capital goods using final output as input, and are subject to adjustment costs. They sell new capital to househods at price $Q_{t}$. The objective of the

representative capital producer is to choose a state-contingent sequence $\left\{I_{t+j}\right\}_{j=0}^{\infty}$ to maximize the expected discounted value of profits:

$$
\mathbb{E}_{t}\left\{\sum_{j=0}^{\infty} \Lambda_{t, t+j}\left[Q_{t+j} I_{t+j}-\left(1+f_{i}\left(I_{t+j} / I_{t+j-1}\right)\right) I_{t+j}\right]\right\}
$$

where the adjustment cost function $f_{i}$ has the same properties as $f_{s}$. From profit maximization, we obtain that the price of capital goods is equal to the marginal cost of investment goods production:

$$
Q_{t}=1+f_{i}\left(I_{t} / I_{t-1}\right)+\frac{I_{t}}{I_{t-1}} f_{i}^{\prime}\left(I_{t} / I_{t-1}\right)-\mathbb{E}_{t}\left[\Lambda_{t+1}\left(\frac{I_{t+1}}{I_{t}}\right)^{2} f_{i}^{\prime}\left(I_{t+1} / I_{t}\right)\right]
$$

The aggregate stock of physical capital then follows the law of motion below:

$$
K_{t+1}=(1-\delta) K_{t}+I_{t}
$$

Equipment producers face a problem analogous to that of capital producers, with a similar adjustment cost function, denoted $f_{m}$. Letting equipment goods produced by the (representative) equipment producer be $I_{t}^{m}$, the latter's objective is the same as (20) replacing $Q_{t+s}$ by $Q_{t+s}^{m}$ and $I_{t+s}$ by $I_{t+s}^{m}$, and with function $f_{m}$ instead of $f_{i}$. The market for equipment goods must clear in the aggregate, and so we must have $I_{t}^{m}=\left(Z_{t}-A_{t}\right) M_{t}$.

\subsection{Employment agencies}

As in Erceg, Henderson and Levin (2000), there is a continuum of households indexed by $i \in[0,1]$, each of which is a monopolistic supplier of specialized labor $L_{i, t}$. A large number of competitive "employment agencies" combine specialized labor into a homogeneous labor input used by intermediate goods producers, according to

$$
L_{t}=\left[\int_{0}^{1} L_{i, t}^{\frac{\omega_{l}-1}{\omega_{l}}} d j\right]^{\frac{\omega_{l}}{\omega_{l}-1}}
$$

From employment agencies' cost minimization, demand for labor variety $i$ is

$$
L_{i, t}=\left(\frac{W_{i, t}}{W_{t}}\right)^{-\omega_{l}} L_{t}
$$


where $W_{i, t}$ is the nominal wage received by supplier of labor of type $i$ and the wage paid by intermediates' producers is

$$
W_{t}=\left[\int_{0}^{1} W_{i, t}^{1-\omega_{l}} d j\right]^{\frac{1}{1-\omega_{l}}}
$$

\subsection{Households}

Household $i$ seeks to maximize the utility function

$$
\mathbb{E}_{t}\left\{\sum_{j=0}^{\infty} \beta^{j}\left[\log \left(C_{t+j}-h C_{t+j-1}\right)-\frac{\chi}{1+\epsilon} L_{i, t+j}^{1+\epsilon}\right]\right\}
$$

subject to a sequence of budget constraints

$$
C_{t}+\frac{B_{t+1}}{P_{t}}+Q_{t} K_{t+1} \leq \frac{W_{i, t}}{P_{t}} L_{i, t}+\mathcal{Q}_{i, t}+R_{t} \frac{B_{t}}{P_{t}}+\left[R_{t}^{k}+(1-\delta) Q_{t}\right] K_{t}+\widetilde{\Pi}_{t}
$$

Here $C_{t}$ is consumption, $B_{t}$ is holdings of the nominal riskless bond, $Q_{t}$ is the real price of capital, $\mathcal{Q}_{i, t}$ is the net cash flow from household $i$ 's portfolio of state-contingent securities, and $\widetilde{\Pi}_{t}$ is total firm profits distributed to the household. The parameter $h$, satisfying $0<h<1$, governs the extent of consumption habits.

As in Erceg et al. (2000), every period a fraction $\theta_{w}$ of households cannot freely set the wage, but instead follows the indexation rule

$$
W_{i, t}=W_{i, t-1} \bar{g} \pi_{t-1}^{\iota w} \bar{\pi}^{1-\iota_{w}}
$$

The remaining fraction of households sets an optimal wage by solving

$$
\max _{W_{t}^{*}} \mathbb{E}_{t}\left\{\sum_{j=0}^{\infty}\left(\theta_{w} \beta\right)^{j}\left[-\frac{\chi}{1+\epsilon} L_{i, t+j}^{1+\epsilon}+\frac{U_{C, t+j}}{P_{t+j}} L_{i, t+j} W_{t}^{*} \prod_{k=1}^{j} \bar{g} \pi_{t+k-1}^{\iota w} \bar{\pi}^{1-\iota_{w}}\right]\right\}
$$

subject to the labor demand function (24). 


\subsection{Central bank and resource constraint}

We suppose that the central bank sets the nominal interest rate $R_{t}$ according to the following Taylor rule:

$$
R_{t}=\frac{\bar{g}}{\beta} \bar{\pi}\left(\frac{\pi_{t}}{\bar{\pi}}\right)^{\gamma_{\pi}}\left(\frac{y_{t}}{y_{t}^{p o t}}\right)^{\gamma_{y}} \Delta_{t}^{r}
$$

where $y_{t} \equiv Y_{t} / A_{t}$ is detrended output, and where $y_{t}^{\text {pot }}$ denotes (detrended) potential output, defined as the equilibrium level of output that would result under perfectly flexible prices and wages. Thus, the rule targets a measure of slack that ignores the "gap" in technology $A_{t} \cdot{ }^{7}$ We use this policy as a baseline as it is likely a good approximation of the measures of slack considered by central banks in practice. In Appendix E, we explore the implications of a rule that instead uses $Y_{t} / Y_{t}^{\text {pot }}$ as the measure of the output gap, and we also consider (within the context of a simplified model) an alternative rule that targets deviations from efficient (i.e., first-best) output.

The rule includes an exogenous monetary policy shock, given by the variable $\Delta_{t}^{r}$, which follows the stochastic process $\log \left(\Delta_{t}^{r}\right)=\rho_{r} \log \left(\Delta_{t-1}^{r}\right)+\epsilon_{t}^{r}$.

The aggregate resource constraint is given by

$$
Y_{t}=C_{t}+\left[1+f_{i}\left(I_{t} / I_{t-1}\right)\right] I_{t}+\left[1+f_{m}\left(I_{t}^{m} / I_{t-1}^{m}\right)\right] I_{t}^{m}+\left[1+f_{s}\left(S_{t} / S_{t-1}\right)\right] S_{t}
$$

Final output is used for consumption, investment, adoption and innovation. To a first order, $Y_{t} \approx Y_{t}^{w}=A_{t}^{\frac{1}{\vartheta-1}} K_{t}^{\alpha} L_{t}^{1-\alpha}$, i.e. wholesale and final output are approximately equal.

This completes the description of the model. Appendix D contains the complete set of equilibrium conditions.

\subsection{Comparison with the literature}

Here we describe the main differences between our model and the related frameworks in Bianchi et al. (2014) and Anzoategui et al. (2017). Our model of innovation, like that in Comin and Gertler (2006) and Anzoategui et al. (2017), is based on the expanding-variety framework due to Romer (1990), while Bianchi et al. (2014) use a vertical-innovations setting. In addition, we also follow Comin and Gertler (2006) and Anzoategui et al. (2017) in explicitly capturing technology diffusion lags, different from Bianchi et al. (2014).

Overall, our model is much closer to Anzoategui et al. (2017) and Comin and Gertler

\footnotetext{
${ }^{7}$ An equivalent formulation would be a rule which assumes that technology in the potential economy is equal to technology in the actual economy, $A_{t}$.
} 
(2006), with a couple of notable exceptions. First, we allow R\&D to have a positive impact on adoption, thus inducing a form of complementarity between the two activities. The motivation is that R\&D activity may not just reflect the pure invention of new goods, but may also reflect in part its role in facilitating the implementation of existing innovations - as argued, for example, by Griffith et al. (2004). As we explain in detail in 3.2, this feature of the model proves very important in allowing the model to deliver realistic dynamic effects of $R \& D$ on TFP. Second, we introduce costs of adjusting the level of both R\&D and adoption expenditure. This feature is also important for the model's empirical performance, for otherwise the model delivers excessive volatility of $R \& D$ and adoption spending, and unrealistic dynamics of R\&D following monetary policy shocks.

\section{Parameter values and model assessment}

This section describes the parameterization of the model and provides an assessment of the model's empirical performance. We partition the parameters into two sets: the first set contains mostly standard preference and technology parameters that we calibrate following the existing literature, as described in section 3.1 below. The second set contains parameters that we estimate, which govern the effects of R\&D on TFP. The key parameters within this set are the elasticity of innovation to $\mathrm{R} \& \mathrm{D}, \eta$, and the elasticity of the adoption rate to aggregate R\&D, $\nu$. To estimate these parameters, we first identify the dynamic effects of R\&D on TFP using U.S. data, and then require the model to match the identified dynamics. Section 3.2 describes our estimation procedure in detail.

Section 3.3 then turns to model assessment. We perform this exercise in two ways. We first examine how the effects of an R\&D shock in the model compare against those from an identified VAR which, in addition to TFP, includes a broader set of standard macroeconomic variables. We also compare the effects of a monetary shock in the model (including on R\&D and TFP) to a VAR-based estimate of the effects of an identified monetary policy shock. The model, we find, does reasonably well along both dimensions.

\subsection{Calibrated parameters}

We calibrate the model at an annual frequency. The calibrated parameter values are shown in Table 1. Our calibration for common preference and technology parameters is relatively standard. We set the discount factor, $\beta$, to 0.9975, to deliver a balanced-growth-path real interest rate of 1 percent annually. Several recent studies (e.g. Reifschneider (2016)) calibrate a similarly low value for the long-run real interest rate, consistent with the decline in estimates 
Table 1: Calibrated Parameters

\begin{tabular}{lcl}
\hline \hline & & \\
Symbol & Value & Description \\
\hline$\beta$ & 0.9975 & Discount factor \\
$\alpha$ & 0.33 & Capital Share \\
$\delta$ & 0.1 & Capital depreciation \\
$\epsilon^{-1}$ & 2 & Frisch labor supply elasticity \\
$h$ & 0.50 & Habit \\
$\omega$ & 6 & Elasticity of substitution across retailers \\
$\omega_{l}$ & 6 & Elasticity of substitution across labor types \\
$\theta$ & 0.75 & Probability of keeping price fixed \\
$\theta_{w}$ & 0.65 & Probability of keeping wage fixed \\
$\iota_{p}$ & 0.50 & Degree of price indexation to past inflation \\
$\iota_{w}$ & 0.50 & Degree of wage indexation to past inflation \\
$100(\bar{\pi}-1)$ & 2 & Steady-state (net) inflation \\
$\gamma_{\pi}$ & 1.5 & Inflation coefficient of the Taylor rule \\
$\gamma_{y}$ & 1.0 & Output gap coefficient of the Taylor rule \\
$\vartheta$ & 2.4925 & Intermediates producers' elasticity of substitution \\
$\phi$ & 0.90 & Obsolescence of technologies \\
$\rho_{\lambda}$ & 0.925 & Adoption elasticity \\
$\bar{L}$ & 1 & Steady-state labor \\
$100\left(\bar{g} \frac{1}{\vartheta-1}-1\right)$ & 0.5 & Steady-state (net) TFP growth \\
$\bar{\lambda}$ & 0.20 & Steady-state adoption probability \\
$f_{i}^{\prime \prime}$ & 1 & Investment adjustment costs \\
$f_{s}^{\prime \prime}$ & 4 & R\&D adjustment costs \\
$f_{m}^{\prime \prime}$ & 4 & Adoption equipment adjustment costs \\
$\rho_{r}$ & 0.55 & Monetary shock persistence \\
& &
\end{tabular}


of the U.S. natural rate of interest (see, for example, Holston, Laubach and Williams (2017)). The capital share $\alpha$ is set to 0.33 , and the capital depreciation rate is $\delta=0.1$. We calibrate $\epsilon$ to 0.5 , resulting in a Frisch elasticity of labor supply of $2 .{ }^{8}$ The habit parameter, $h$, is set to 0.50, somewhat below typical estimates, to account for the fact that these estimates typically result from quarterly data while our model is annual.

Turning to the parameters governing price setting, we set the elasticity of substitution across retailers, $\omega$, to 6 , and we set the same value for the elasticity of substitution across labor types, $\omega_{l}$. These values yield a steady-state price and wage markup of 20 percent, in the neighborhood of values commonly found in the literature (e.g. Justiniano et al. (2010), Christiano et al. (2005)). We emphasize, however, that our results are insensitive to variations around these values. We set the price and wage rigidity parameters, $\theta$ and $\theta_{w}$, to 0.75 and 0.65 respectively. These choices result from converting to annual frequency the quarterly estimates from Anzoategui et al. (2017). Similarly high levels of nominal rigidity are common in recent studies - for example, Del Negro, Giannoni and Schorfheide (2015). The literature features a fairly wide range of values for the price and wage indexation parameters, ranging from full indexation (e.g., Christiano et al. (2005)) to relatively low values (e.g. Justiniano et al. (2010)). As a compromise between the two extremes, we set $\iota_{p}=\iota_{w}=0.5$. The steady-state inflation rate is calibrated to 2 percent per year. Finally, we set the policy rule coefficients on inflation and the output gap, $\gamma_{\pi}$ and $\gamma_{y}$, to 1.5 and 1.0 respectively. The resulting rule provides a reasonably good description of the FOMC's actual behavior in the years prior to the Great Recession, as argued by Reifschneider (2016), and has been shown to have good stabilization properties across different models (see Taylor (1999)).

The parameter governing the elasticity of final output with respect to intermediates, $\vartheta$, is chosen so that the technological level $A_{t}$ takes the purely labor-augmenting form, which amounts to imposing the restriction $(1-\alpha)(\vartheta-1)=1 .^{9}$ This restriction implies that there exists a balanced growth path along which output is proportional to TFP, and therefore profits per period $\Pi_{t}$ are stationary (see equation (14)), which simplifies somewhat the characterization of the balanced growth path. Given the choice for $\alpha$, the resulting value for the intermediate goods markup is $\vartheta /(\vartheta-1)=1.67$, close to the value of 1.6 set by Comin and Gertler (2006).

We set the technology obsolescence rate, $1-\phi$, to 10 percent annually, similar to Anzoategui et al. (2017), who rely on estimates of technological obsolescence from Caballero and Jaffe (1993). We also follow Anzoategui et al. (2017) and set the elasticity of the adoption

\footnotetext{
${ }^{8}$ We have also experimented with values of the Frisch elasticity of 1 and 0.75 , and found that our key results are relatively unchanged under these alternative values.

${ }^{9}$ Kung and Schmid (2015) make a similar parameter restriction.
} 
probability to adoption expenditure, $\rho_{\lambda}$, to 0.925 (also similar to the value originally set by Comin and Gertler (2006)). This value helps deliver a realistic ratio of R\&D to GDP in steady state, and is also consistent with measures of the cyclicality of technology diffusion, Anzoategui et al. (2017) document.

To set the parameters $\chi$ (labor disutility), $\zeta$ (productivity of R\&D), and $\kappa_{\lambda}$ (constant in the adoption rate), we target properties of the model's balanced growth path. In particular, we normalize the level of labor $\bar{L}$ to unity, and target a TFP growth rate of $0.5 \%$ and an adoption rate of 0.20 . The target for TFP growth is the average U.S. TFP growth rate since 2005. The adoption rate target follows Comin and Gertler (2006) and Anzoategui et al. (2017), who rely on evidence on average technology adoption lags. The average adoption lag in the model is given by $\bar{\lambda}^{-1}$. The chosen value for $\bar{\lambda}$ thus implies an average adoption lag of five years. Given these targets, we then back out the parameters $\chi, \zeta$ and $\kappa_{\lambda}$. In our estimation procedure below, we always keep the targets fixed as we search over the estimated parameters, thus ensuring that our estimates are always consistent with the targeted values for the balanced growth path.

Turning to the adjustment costs parameters, we set $f_{i}^{\prime \prime}$, governing the adjustment costs of investment in physical capital, to unity, a value that lies somewhat below the range of estimates typically found in the literature (from a value of around 1.7 estimated by Primiceri et al. (2006) to much higher values found by, e.g., Smets and Wouters (2007)). Part of the reason why we choose a lower value is that adjustment costs are likely less pronounced at the annual frequency than at the quarterly frequency. In addition, we have found that even conditional on a value of unity, our model generates a relatively small response of investment to a monetary policy shock, likely due to the presence of other highly interest-elastic components of spending (namely, adoption and R\&D). We calibrate the R\&D adjustment cost parameter, $f_{s}^{\prime \prime}$, to match the relative volatility of R\&D growth to investment growth in the data. U.S. R\&D growth is about two-thirds as volatile as investment growth, which our model matches when setting $f_{s}^{\prime \prime}=4 .^{10}$ Given that comprehensive measures of adoption expenditures are not available, we suppose that adjustment costs to adoption are as large as for R\&D, and accordingly set $f_{m}^{\prime \prime}=f_{s}^{\prime \prime}$. Finally, we set the parameter governing the persistence of the monetary shock, $\rho_{m}$, to 0.55 , based on the autocorrelation of Taylor rule residuals (given our calibrated rule) in the pre-Great Recession period.

\footnotetext{
${ }^{10}$ To calculate this ratio, we simulate the model conditional on shocks to $\Delta_{t}^{s}$ and $\Delta_{t}^{r}$, calibrated such that the model delivers realistic volatilities of the $R \& D$ growth and the Fed funds rate.
} 


\subsection{Estimated parameters}

We begin by describing a small-scale VAR we use as means of gauging the quantitative effects of R\&D on TFP. The reduced-form empirical specification is the following first-order system:

$$
\left[\begin{array}{c}
y_{t}^{u s} \\
t f p_{t}^{u s} \\
r d_{t}^{u s}
\end{array}\right]=c^{u s}+B^{u s}\left[\begin{array}{c}
y_{t-1}^{u s} \\
t f p_{t-1}^{u s} \\
r d_{t-1}^{u s}
\end{array}\right]+u_{t}^{u s}
$$

Here $y_{t}^{u s}, t f p_{t}^{u s}$, and $r d_{t}^{u s}$ represent, respectively, real GDP, TFP, and real business-sector R\&D expenditure (obtained from the NSF). All variables are in logs. The frequency is annual, and observations start in 1953. We estimate the above system by least squares. The coefficients to be estimated include a vector of constants, $c^{u s}$, a matrix of autoregressive coefficients, $B^{u s}$, and the variance-covariance matrix of the reduced-form residuals $u_{t}$. We include all three variables in levels, given the likely presence of cointegrating relationships among them. ${ }^{11}$

To identify structural shocks to R\&D, we rely on a lower-triangular Choleski factorization of the variance-covariance matrix of the reduced-form residuals. Given the variable ordering in (32), this identification scheme imposes the restriction that TFP does not respond contemporaneously to structural innovations in $\mathrm{R} \& \mathrm{D}$. This is a natural assumption: it captures the idea that it takes time for R\&D expenditure (an input into the innovation process) to result in new technologies that become implemented and used in production. Macroeconomic models featuring technological innovation and adoption, including ours, generally satisfy this restriction. We also believe it is important to allow both TFP and R\&D to respond to shocks to GDP, which is accomplished by placing GDP first in the VAR. This allows us to control for business-cycle effects which might induce comovement between R\&D and TFP if, for example, the short-run behavior of the latter partly reflects mismeasurement.

The black solid line in Figure 2 shows the dynamic effects of a one-standard-deviation identified shock to R\&D expenditure: R\&D rises by about 4 percent on impact, and then gradually declines. The shock impacts TFP significantly, albeit with a delay: at its peakwhich occurs after about seven years - the response of the level of TFP reaches nearly $0.5 \%$, with half of the full effect materializing about three years after the initial shock. Further, the TFP increase induced by the shock is highly persistent, and its level stays high long after R\&D has returned to baseline. The natural interpretation is that a rise in R\&D for reasons unrelated

\footnotetext{
${ }^{11}$ The same approach is followed, for example, by Christiano et al. (2005).
} 
Figure 2: Small-scale VAR v. model responses to R\&D shock
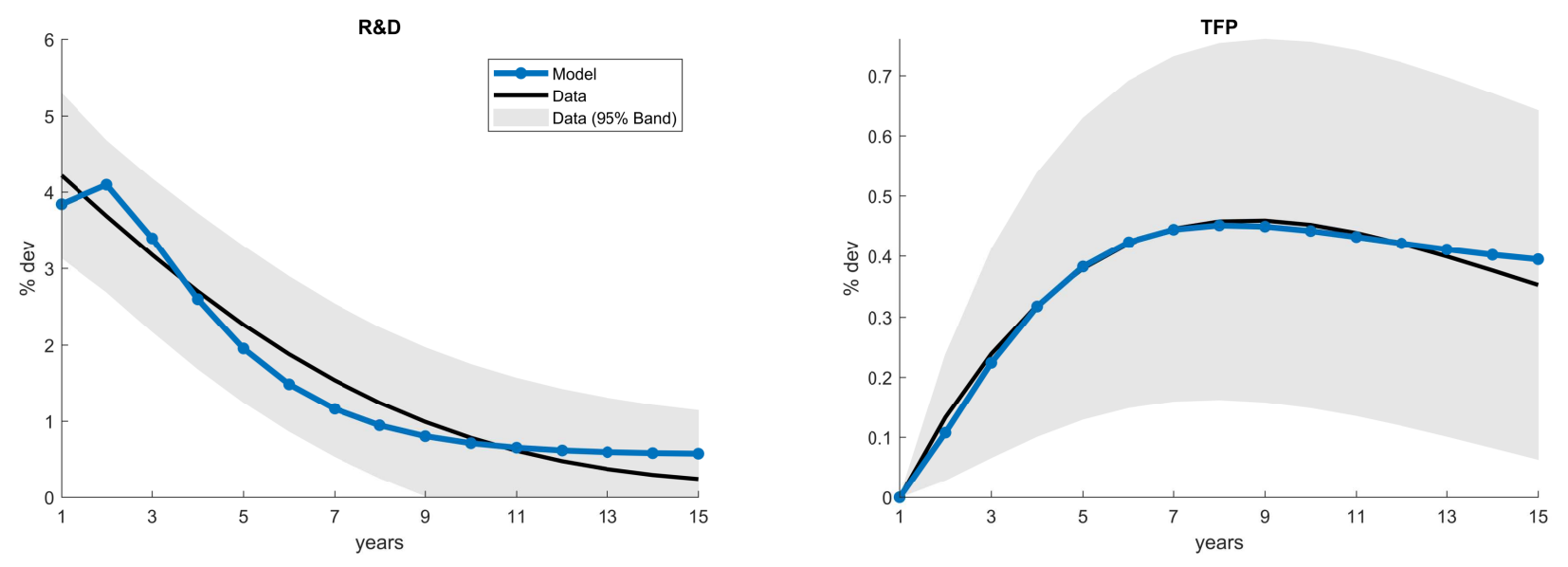

Note: The black solid lines show the empirical responses to an identified R\&D shock in the VAR 32, and the shaded areas indicate confidence intervals. The solid blue lines with circles show the model's responses to a shock to the R\&D wedge at the estimated parameter values.

to current TFP (or to the state of the economy, as proxied for by real GDP) accelerates the development of technological innovations which, after some time, become implemented in production and eventually improve firms' productivity. ${ }^{12}$

We have investigated whether the effects of R\&D on TFP just documented also hold within a sample of advanced economies, and found that they do. The analysis is shown in appendix A. We find the impact of R\&D on TFP to be somewhat weaker within a panel of about 20 advanced economies compared to the U.S. However, when we consider only countries with high R\&D to GDP ratios we find substantially stronger effects than with the full panel. In addition, we have also considered different measures of TFP in the case of the U.S. (including those calculated by Fernald (2014)), and found our results to be robust to these alternative measures (see appendix B).

We now turn to estimating the model's key parameters driving the effect of $\mathrm{R} \& \mathrm{D}$ on TFP, by requiring the model-generated impulse responses of $\mathrm{R} \& \mathrm{D}$ and TFP to be as close as possible to the VAR-based ones. To initiate movement in $R \& D$, we use a shock to the R\&D wedge $\Delta_{t}^{s}$. We estimate four parameters: the elasticity of new innovations with respect

\footnotetext{
${ }^{12} \mathrm{An}$ alternative possibility is that the results in Figure 2 reflect the effects of a rise in future TFP (for exogenous reasons), which is foreseen by firms and leads them to increase R\&D expenditure today. One way to test for that possibility is to use the same identification scheme, but replacing R\&D for aggregate investment. Under the hypothesis that our results are driven by the effect of anticipated future TFP movements, we would expect to find a similar pattern using investment in place of $\mathrm{R} \& \mathrm{D}$, as the anticipation of high future TFP should also lead firms to increase investment. However, we find that TFP actually falls following a rise in investment (although the decline is not statistically significant).
} 
Table 2: Estimated Parameters

\begin{tabular}{lcl}
\hline \hline Symbol & Value & Description \\
\hline & & \\
$\eta$ & 0.30 & Elasticity of technology creation to R\&D \\
$\nu$ & 0.29 & R\&D spillover to adoption \\
$\rho_{s}$ & 0.39 & Persistence coefficient of $\Delta_{t}^{s}$ \\
$\sigma_{s}$ & 0.17 & Size of impulse to $\Delta_{t}^{s}$
\end{tabular}

to R\&D, $\eta$; the magnitude of the spillover from aggregate R\&D to adoption, $\nu$; the firstorder autoregressive coefficient of the innovation wedge, $\rho_{s}$; and the size of the impulse to the innovation wedge, $\sigma_{s}$. Let the subset of estimated model parameters be $\varepsilon \equiv\left(\eta, \nu, \rho_{s}, \sigma_{s}\right)$. Let also $\Psi(\varepsilon)$ denote the mapping from $\varepsilon$ to the model's impulse responses to the initiating shock to $\Delta_{t}^{s}$, and let $\hat{\Psi}$ be the empirical impulse responses of R\&D and TFP to an identified R\&D shock, as shown in Figure 2. We use the first 15 years of each response, so $\hat{\Psi}$ contains 30 elements. We estimate $\varepsilon$ by solving

$$
\min _{\varepsilon}[\hat{\Psi}-\Psi(\varepsilon)]^{\prime} \mathcal{V}^{-1}[\hat{\Psi}-\Psi(\varepsilon)]
$$

Here $\mathcal{V}$ denotes a diagonal matrix with the variances of the estimated impulse responses along the main diagonal. The weighting matrix $\mathcal{V}$ gives relatively more weight to more precise estimates in the optimization problem above.

Table 2 contains the resulting parameter estimates. Our estimate of the elasticity of aggregate new technology production with respect to aggregate $\mathrm{R} \& \mathrm{D}$ expenditure, $\eta$, is 0.30 , a value lower than used by Comin and Gertler (2006) but in the vicinity of the value estimated by Anzoategui et al. (2017). The estimate of the R\&D spillover to adoption is 0.29 , indicating that the data favors an increase in adoption rates to occur alongside the rise in $R \& D$. The estimate of first-order autoregressive coefficient $\rho_{s}$ is 0.39 , and the size of the impulse to $\Delta_{s}$ is 17 percent.

Figure 2 plots the empirical impulse responses along with the model-generated responses, computed using the estimated parameter values in Table 2. The model tracks the empirical movements in R\&D and TFP well. As seen in the Figure, in both the model and the data, an increase in R\&D of about 4 percent initially leads the level of TFP to rise about 0.4 in the medium-run, and the dynamic path of the TFP rise in the model is very close to its empirical counterpart.

We next document the model's transmission from R\&D to TFP, and illustrate the role 
Figure 3: R\&D shock transmission, sensitivity to $\eta$ and $\nu$
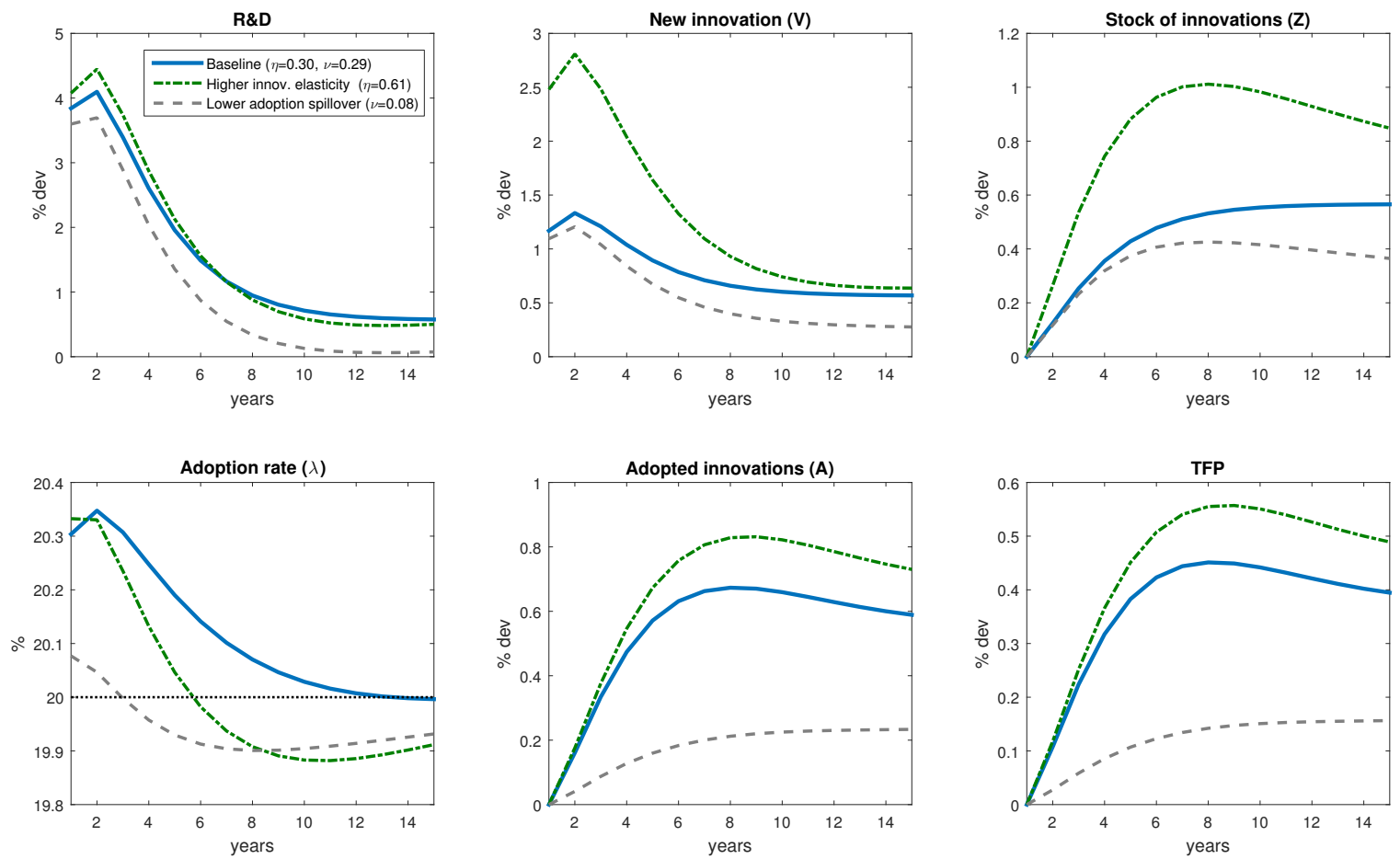

Note: The solid blue line represents the impulse responses at the estimated parameter values. The green dash-dotted line shows the responses when doubling $\eta$ relative to its estimated value, and the grey dashed line shows the responses when reducing $\nu$ to one-fourth of its estimated value.

of the parameters $\eta$ and $\nu$ in shaping the model's responses. As we show below, both the magnitude and the time path of the empirical TFP response help identify $\eta$ and $\nu$. Figure 3 shows the impulse responses of several variables pertaining to the innovation and adoption sectors at our estimated values (blue solid line), along with the responses resulting from setting $\eta=0.61$ (i.e. twice its estimated value), shown by the green dash-dotted line, and from setting $\nu=0.08$ (i.e. one-fourth of its estimate). Throughout we continue to maintain the steady-state targets for $\bar{L}, \bar{g}$ and $\bar{\lambda}$. As shown by the blue solid line in the Figure, the increase in R\&D spurs the creation of new innovations $V_{t}$, which add to the stock of existing technologies, $Z_{t}$. As these innovations become adopted (which occurs at a higher rate for some time, due to the adoption spillover) the stock of technologies in use $\left(A_{t}\right)$ rises, accounting for the rise in TFP.

Note that with a higher elasticity of innovation to $\mathrm{R} \& \mathrm{D}(\eta)$, the increase in $V_{t}$ from a given rise in $\mathrm{R} \& \mathrm{D}$ becomes larger. As a consequence, the total stock of technologies $Z_{t}$ rises by more, ultimately leading to a higher response of the level of the TFP. In turn, when the spillover from $\mathrm{R} \& \mathrm{D}$ to adoption is weaker (i.e. $\nu$ is lower) the overall rise in TFP is smaller, this time 
due to a response of adoption which is mostly negative throughout the simulation (note in this case both $V_{t}$ and $Z_{t}$ exhibit roughly similar dynamics as under the baseline parameter estimates). In addition, lower $\nu$ also makes the dynamic response of TFP substantially flatter: with the baseline estimates, the peak response of TFP occurs relatively soon, after about 7 years, and levels off thereafter. By contrast, a lower $\nu$ implies a much more gradual effect on TFP, which continues to rise throughout the simulation horizon. This explains why the data tends to favor a larger $\nu$, as such a gradual TFP rise in the model is at odds with its empirical counterpart. Thus, given that the parameters $\eta$ and $\nu$ have different implications for the path of TFP given a path of R\&D, it is possible to identify both parameters given the empirical responses of R\&D and TFP.

We next explore the implications of assuming no spillovers from R\&D to adoption. To this end, we first reestimate the parameter vector $\varepsilon$, this time imposing $\nu=0$ (no effect of aggregate $\mathrm{R} \& \mathrm{D}$ on the adoption rate). The resulting parameter estimates are $\eta=0.99$, $\rho_{s}=0.75$ and $\sigma_{s}=0.079$. Figure 4 shows the model's behavior in this case (green dashdotted line), compared to our baseline case. As discussed earlier, the baseline case has the adoption rate rise above its steady-state value (of twenty percent per year) for a few years after the shock. By contrast, absent the spillover, the adoption rate falls throughout the simulation horizon. This is the result of a type of substitution effect: given the decrease in the innovation wedge - which works to make investments in R\&D more desirable - agents optimally direct resources toward that activity, and away from other activities (including technology adoption). ${ }^{13}$ The lower adoption rate then makes it very hard for the model to match the data: note from the bottom-left panel that the increase in $A_{t}$ with $\nu=0$ is very gradual, and clearly at odds with the data. This is the case even though the elasticity of innovation to R\&D is much larger in this case (0.99 compared to 0.30$)$.

\subsection{Model assessment}

Next, we turn to an assessment of the model's performance against the data. We do so in two ways: first, we augment the VAR to include a broader set of macroeconomic variables, and compare the effects of R\&D shocks to those obtained from the model. This largerscale VAR includes aggregate investment (excluding R\&D), consumption, inflation (measured by the GDP deflator) and the monetary policy rate (measured by the Wu and Xia (2016) shadow rate). We order the additional variables after $R \& D$, so they are allowed to respond contemporaneously to R\&D shocks. Second, we obtain estimates on the effects of monetary

\footnotetext{
${ }^{13}$ Note that because the rise in innovation $V_{t}$ raises to stock of unadopted technologies, $Z_{t}-A_{t}$, aggregate adoption expenditures would rise even if each adopter kept individual adoption expenditure (and hence adoption rates) constant.
} 
Figure 4: R\&D shock, baseline v. no adoption spillover
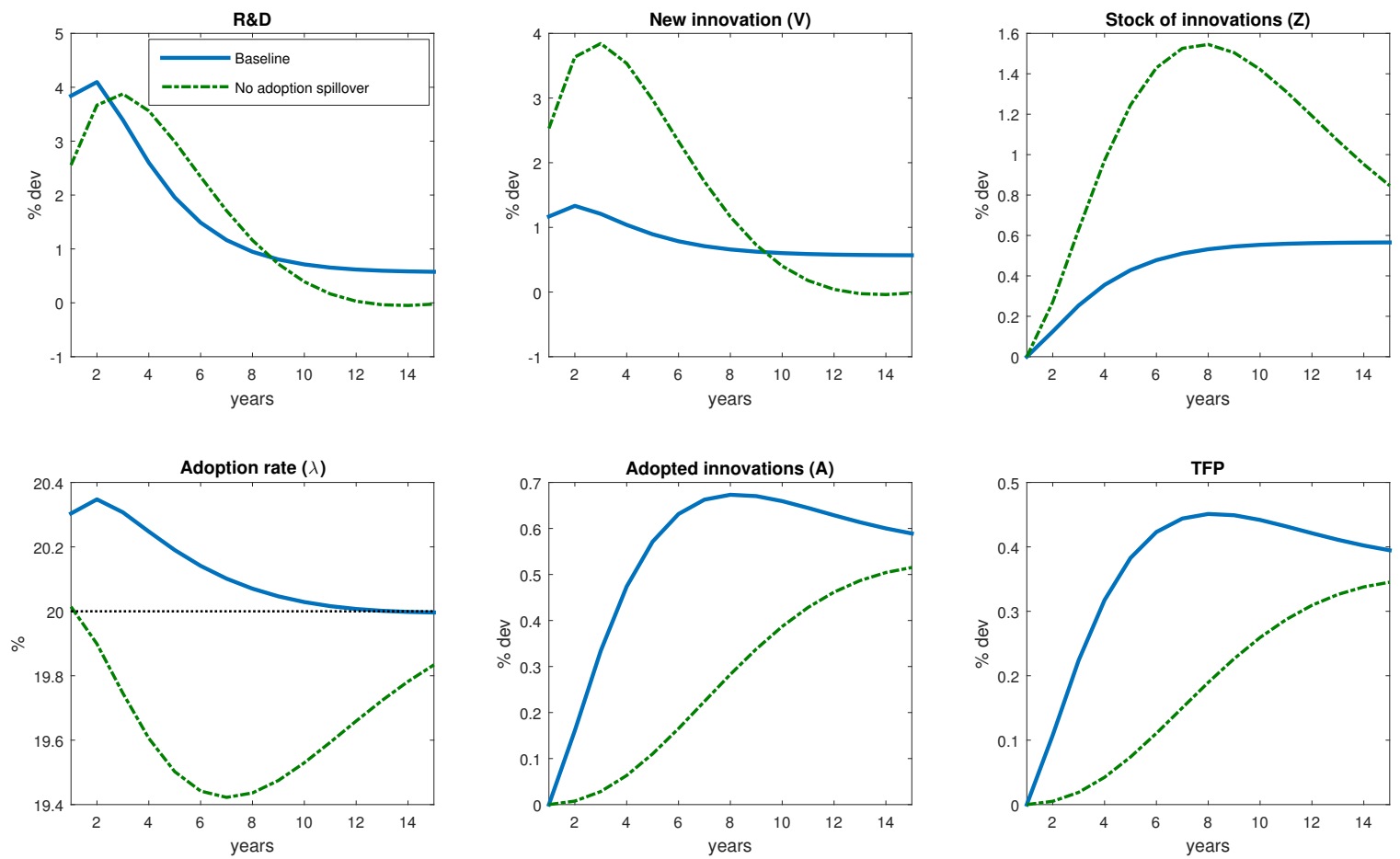

Note: The solid blue line represents the impulse responses at the estimated parameter values, and the green dash-dotted line shows the responses in a (reestimated) model that imposes $\nu=0$ (no adoption spillover). The reestimated parameter values in the no-spillover model are $\eta=0.99, \rho_{s}=0.75, \sigma_{s}=0.079$.

policy shocks on the same set of variables, and compare them against the effects of monetary policy shocks predicted by the model.

Figure 5 plots the empirical responses for the larger set of variables (shown by the black solid lines), along with their model counterparts (the blue circled lines). The model matches macroeconomic aggregates reasonably well. It roughly matches the overall quantitative increase in GDP. It also does a good job of reproducing the initially muted response of consumption and investment (the latter actually declines somewhat on impact, both in the data and in the model), as well as their eventual rise as the boom in TFP strengthens. Inflation drops in the model as well as in the data, albeit the model underpredicts its decline somewhat. The Fed funds rate declines a bit in the data, while in the model it rises initially (due to a rise in the natural rate, resulting from higher expected consumption growth) and then flattens out.

Next, we describe the VAR we use to identify the effects of monetary shocks in the data. Because it is not feasible to accurately capture monetary shocks within an annual setting, we switch to the quarterly frequency. We use data on GDP, R\&D, consumption, investment, TFP, inflation and the Fed funds rate. The NSF does not produce data on R\&D spending 
Figure 5: Large-scale VAR v. model responses to R\&D shock
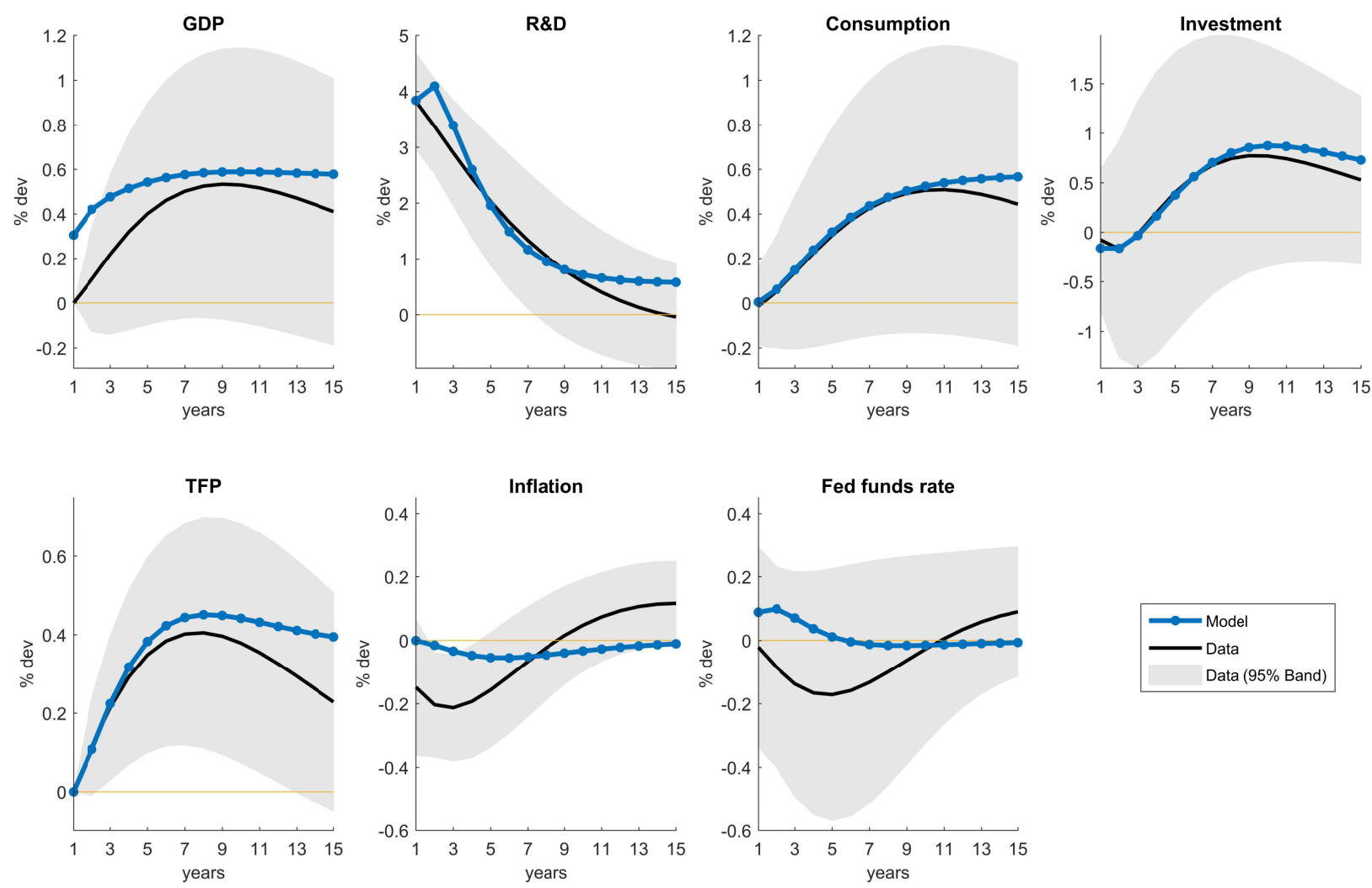

Note: Responses to an identified R\&D shock in the larger-scale U.S. VAR (black solid lines and shaded areas), along with model impulse responses (blue circled lines).

at the quarterly frequency, so we use the measure from the Bureau of Economic Analysis instead. Given the likely importance of movements in factor utilization at the high frequency, we use a utilization-adjusted TFP measure, as computed by Fernald (2014). We continue to use the shadow Fed funds rate to measure the stance of monetary policy, which allows us to estimate the VAR through end-2016 (including the period in which monetary policy was constrained by the ZLB), although our results are virtually unchanged when we stop in the fourth quarter of 2008. As frequently done in the literature, we identify monetary shocks by ordering the Fed funds rate last in the VAR, thus restricting it to be unable to impact the other variables within the same quarter.

We first briefly describe the effects of an identified monetary shock in the data. The black solid lines in Figure 6 show the responses to a one-standard-deviation decline in the Fed funds rate obtained from the VAR. We average the quarterly responses to obtain annual figures, to ease comparison with the model. Appendix $\mathrm{C}$ contains the original responses at the quarterly frequency. The Fed funds rate drops by 60 basis points and then reverts back relatively 
quickly. The shock induces familiar movements in GDP, consumption, and investment, which respond in a hump-shaped fashion and peak after about 2 years. The policy loosening also causes a small rise in inflation after some delay. The initial fall in inflation is consistent with a short-lived "price-level puzzle" typically found in VAR studies of this type (e.g., Christiano et al. (2015)). Interestingly, the shock also induces a statistically significant increase in R\&D spending, which rises about 40 basis points at its peak (somewhat less than the rise in GDP). The response of $R \& D$ spending is smaller in magnitude than that of investment, as well as somewhat more protracted: investment rises by nearly two percent and peaks after about two years, while the peak in R\&D occurs after 3 to 4 years and reverts back more slowly. This pattern is suggestive of larger adjustment costs of R\&D than of investment. Finally, TFP does not respond significantly in the short run, but rises by between 10 and 20 basis points in the medium run. Further, the rise is statistically significant. ${ }^{14}$ Note that the longer-run TFP increase is consistent with the medium-run behavior of GDP, which also remains elevated by around 20 basis points.

We next compare the VAR-based effects of monetary policy shocks to those predicted by the model. We study the effects of a negative innovation to $\Delta_{t}^{r}$ in the model, sized so that the policy rate falls by 60 basis points in the first year (similar to the data). The effects of the shock are shown by the blue circled lines in Figure 6. The model-based responses are reasonably close to those in the data. If anything, the model underpredicts somewhat the short-run booms in consumption and particularly in investment. The peak response of $R \& D$ in the model is about 40 basis points, very close to the data, although the increase is more persistent. On the other hand, the model generates a smaller rise in TFP than in the data throughout most of the simulation horizon, matching the rise of TFP in the data only after about ten years.

How does monetary policy affect TFP in the model? Figure 7 shows the responses of key variables pertaining to innovation and adoption to the same shock to the policy rate shown in Figure 6. Given nominal rigidities, the drop in the nominal rate engineers a decline in the real interest rate, which due to the increase in expected inflation falls somewhat more than the nominal rate (almost 70 basis points). The decline in the real interest rate contributes to a rise in the marginal values of innovation, $\mathbb{E}_{t}\left(\Lambda_{t, t+1} J_{t+1}\right)$, and of adoption, $\mathbb{E}_{t}\left[\Lambda_{t, t+1}\left(H_{t+1}-J_{t+1}\right)\right]$. In addition, the cyclical upswing resulting from looser monetary policy endogenously raises the market value of new innovations, through an increase in profits to owning a new innovation $\Pi_{t}$. As a result, the magnitude of the increase in the marginal values of innovation and adoption

\footnotetext{
${ }^{14}$ When we run the same VAR but using instead the non-utilization-adjusted measure of TFP, we find a short-run boom in TFP following the monetary shock (consistent with higher rates of factor utilization), but obtain a very similar longer-run response.
} 
Figure 6: Monetary VAR v. model responses to monetary shock
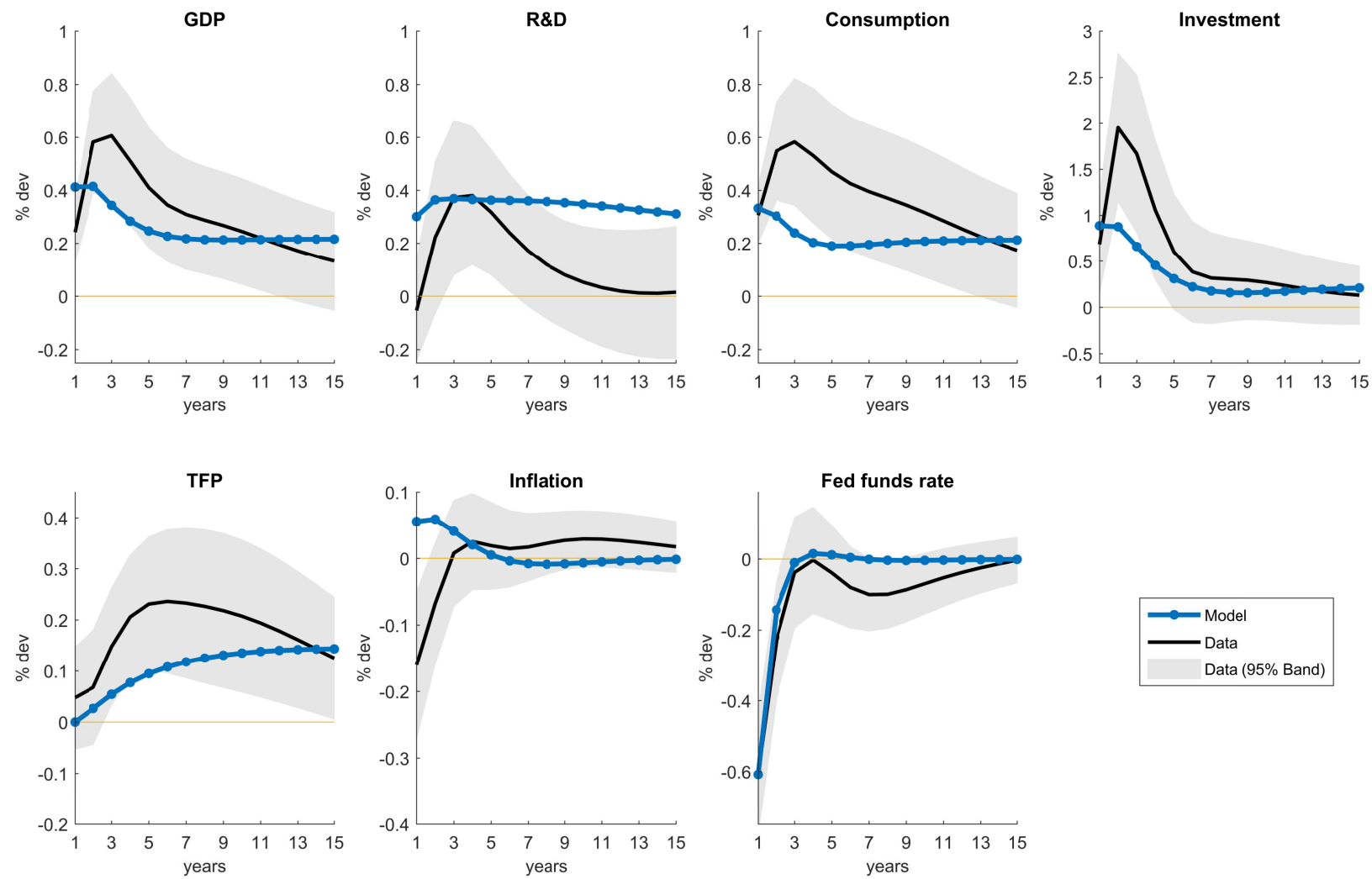

Note: Responses to an identified monetary shock in a VAR (black solid lines and shaded areas), along with model impulse responses to monetary shock (blue circled lines).

is larger than the magnitude of the decline in the real rate, as seen in the bottom left and middle panels of Figure $7 .{ }^{15}$ The higher marginal values of innovation and adoption naturally lead to a rise in R\&D spending (as seen earlier in Figure 6) and in adoption expenditure per unadopted good, $M_{t}$, which increases about as much as R\&D. The result is a rise in both innovation $V_{t}$ and in adoption rates $\lambda_{t}$. The latter are ultimately responsible for the gradual rise in TFP seen in the bottom-left panel of Figure 6.

\section{Experiments}

We next use the model to perform counterfactual experiments. We focus on two specific questions. First, we use the model to explore the implications for TFP of the long period

\footnotetext{
${ }^{15}$ Note that log-linearizing $\mathbb{E}_{t}\left(\Lambda_{t, t+1} J_{t+1}\right)$ and $\mathbb{E}_{t}\left[\Lambda_{t, t+1}\left(H_{t+1}-J_{t+1}\right)\right]$ around the steady state yields, respectively, $-r_{t}+\mathbb{E}_{t}\left\{j_{t+1}\right\}$ and $-r_{t}+\alpha_{H} \mathbb{E}_{t}\left\{h_{t+1}\right\}-\alpha_{J} \mathbb{E}_{t}\left\{h_{t+1}\right\}$, where $r_{t}$ denotes the real interest rate, lowercase letters denote log-deviations of uppercase letters, and $\alpha_{H} \equiv \bar{H} /(\bar{H}-\bar{J}), \alpha_{J} \equiv \bar{J} /(\bar{H}-\bar{J})$.
} 
Figure 7: Monetary shock in the model, endogenous technology variables
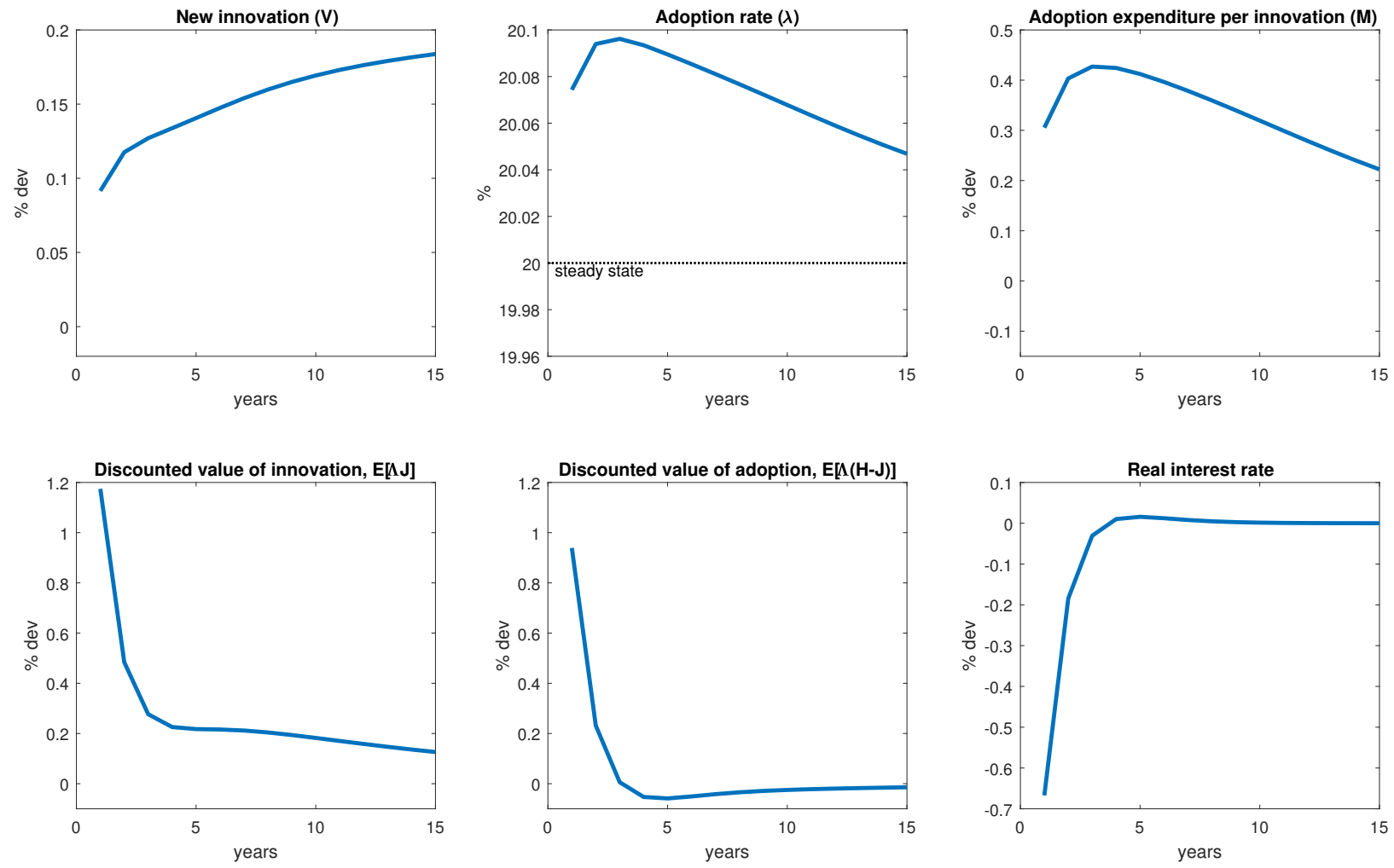

Note: The Figure shows the impulse responses to a monetary shock $\Delta_{t}^{r}$. We size the impulse so that it induces a fall in the nominal interest rate of 60 basis points, as in the monetary VAR.

during which U.S. monetary policy was constrained by the ZLB. Second, we examine the extent to which more-accommodative monetary policy post-2016 can boost future TFP. We address each of these questions in turn.

\subsection{Role of the zero lower bound}

Our first experiment focuses on quantifying the effect of the ZLB constraint on TFP. Our approach is as follows. We first use our calibrated Taylor rule, together with observations on inflation, the output gap, and the Fed funds rate (which was zero from 2009 through 2015) to deduce the historical values of $\Delta_{t}^{r}$ that resulted from enforcing the ZLB on the monetary policy rate. We follow the common practice of approximating the output gap by (the negative of) twice the unemployment gap (i.e. the gap between actual unemployment and the natural rate of unemployment) — as done, for example, in Yellen (2016b) and Reifschneider (2016). Following this approach, our Taylor rule recommends a policy rate deep into negative territory, shown by the grey dash-dotted line in the first panel of Figure 8 . We take the 
difference between the rate prescribed by the Taylor rule and the actual Fed funds rate in this period, shown by the black solid line in the same panel, in order to compute the monetary policy shocks $\Delta_{t}^{r}$ from 2009 to 2014. Our calibrated policy rule implies positive values for $\Delta_{t}^{r}$ from 2009 through 2014, shown by the black solid line in the middle panel, suggesting that the degree of monetary contraction due to the ZLB was substantial. Our experiment then asks the question: how would TFP, and other variables, have evolved if that monetary contraction had been absent? The experiment amounts to analyzing the consequences of setting the shocks in the second panel of Figure 8 to zero. ${ }^{16}$

The remaining panels of Figure 8 show the effect on GDP, inflation, R\&D and TFP, of setting the $\Delta_{t}^{r}$ to 0 from 2009 through 2014 (relative to the "baseline" in which the ZLB was binding throughout). From the last panel, note that the level of TFP rises persistently in the counterfactual, by almost 1.75 percent after about ten years, due to greater innovation and faster adoption. The long-run effects on output are even greater: output rises by 2.5 percent over the long run, as higher TFP leads to more accumulation of physical capital.

Finally, we briefly describe the consequences of the same experiment in a model without the endogenous TFP mechanism, shown by the green dashed line labelled "exogenous growth." In this case, removing the monetary contraction also results in a substantial boost to GDP, with a peak effect of roughly 3.8 percent in 2010-relatively close to the effect in our full model, of about 4.3 percent in the same year. Crucially, however, in this case the boost to GDP is short-lived: by 2016, the level of GDP is back to baseline - in sharp contrast to the model with endogenous TFP, in which GDP is permanently higher absent the monetary shocks enforcing the ZLB.

\subsection{Effect of slower monetary tightening post-2016}

Given the effects of monetary policy on TFP just documented, how much can future monetary policy boost TFP within this setting? We next use the model to illustrate the consequences for future TFP of the pace of monetary policy tightening post-2016. In particular, we consider the following experiment. Suppose a baseline scenario in which the policy rate post-2016 follows the path shown by the black solid line in the top left panel of Figure 9, taken from the FOMC's "projected appropriate policy path" as of June 14, 2017. Under this baseline path, the Fed funds rate reaches 3 percent (its long-run level) in 2019, and averages about 2.75 percent over the period 2017-2020. We then consider an alternative scenario in which monetary policy tightens much more slowly, as shown by the grey dash-dotted line.

\footnotetext{
${ }^{16}$ Of course, given linearity, this experiment is equivalent to feeding the model the sequence $\Delta_{t}^{r}$ in the second panel of Figure 8, multiplied times -1 .
} 
Figure 8: Effects of ZLB constraint
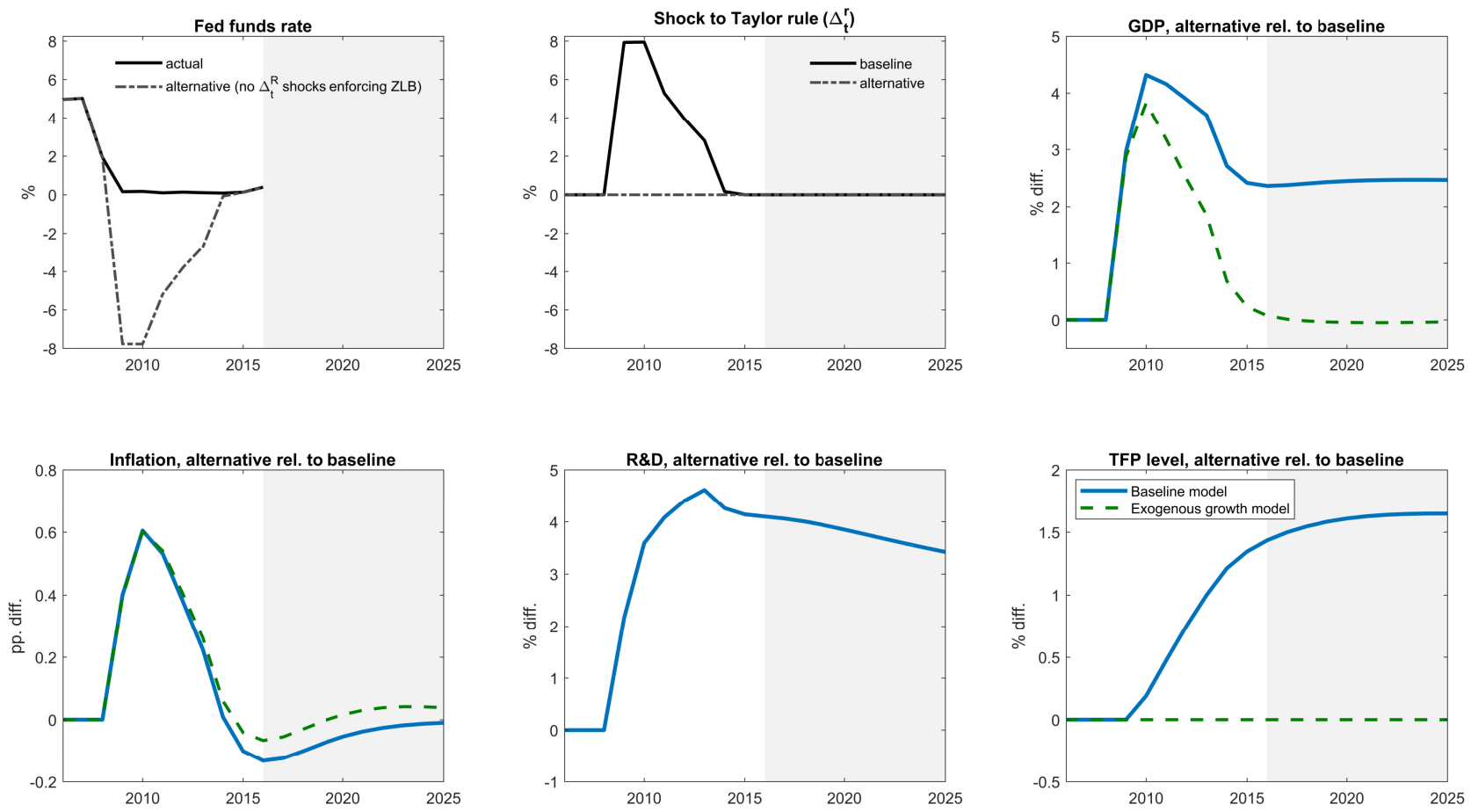

Note: The first panel shows the actual Fed funds rate (solid line) and the Fed funds prescribed by our calibrated Taylor rule, given observations of inflation and the output gap (grey dash-dotted line). The second panel shows the historical shocks to the Taylor rule that enforced the ZLB, calculated as the actual Fed funds rate minus the rate prescribed by the Taylor rule (in the years in which the latter was negative, i.e. 2009 through 2014). In the alternative simulation, we set these shocks to 0. The remaining panels show the effects on GDP, Inflation, R\&D and TFP of setting the monetary shocks to zero. The blue solid line in these panels shows the effects in our baseline model with endogenous TFP, and the green dashed lines show the effects in a model with exogenous TFP.

This scenario assumes that the Fed funds rate does not reach its new long-run level until after 2025 - i.e., more than half a decade later than in the baseline. In the alternative scenario, the policy rate averages only around 2.25 percent in 2017-2025, 50 basis points less than in the baseline. We enforce the alternative scenario via exogenous monetary shocks $\Delta_{t}^{r}$. The shocks required to generate the alternative path of the policy rate are shown in the top middle panel of Figure 9.

The remaining panels again show the effects on GDP, inflation, R\&D and TFP of the alternative policy path. The monetary stimulus boosts TFP, which rises gradually starting in the early 2020's and plateaus at a level almost 1 percent higher by 2030. As before, the longrun effects on GDP are even greater, with its level rising almost 1.5 percent above baseline by the late 2020s. The monetary accommodation leads to a temporary boost in inflation, which 
Figure 9: Effect of slower monetary tightening
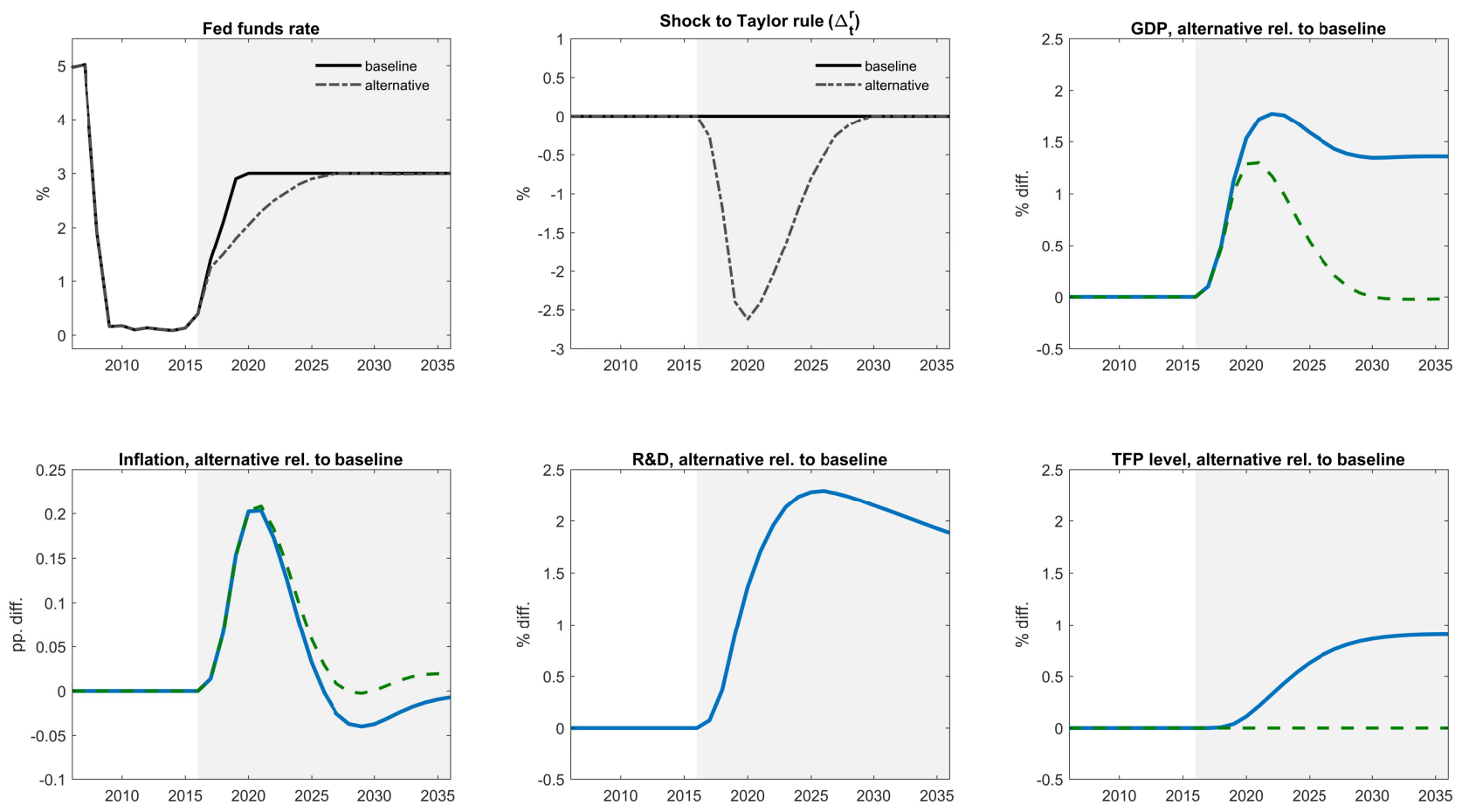

Note: The first panel shows the projected Fed funds rate path (solid line) and the alternative with slower tigthening (grey dash-dotted line). The second panel shows the shocks to the Taylor rule required to generate the alternative path (grey dash-dotte line). The remaining panels show the effects on GDP, Inflation, R\&D and TFP of the alternative policy rate path. The blue solid line in these panels shows the effects in our baseline model with endogenous TFP, and the green dashed lines show the effects in a model with exogenous TFP.

rises 20 basis points in the early 2020s, but then quickly reverts back and remains persistently below baseline in the late 2020s and early 2030s, as the rise in TFP strengthens.

We conclude by comparing the effects in our baseline model to those in a version of the model without endogenous TFP. In the latter case, the output boost due to monetary accommodation is purely temporary, and smaller in magnitude throughout. Note also that in this case, the slower tightening is somewhat less inflationary, as the rise in TFP works to moderate the increase in marginal costs.

\section{Conclusion}

This paper analyzes a framework that provides a link between TFP and monetary policy, via the latter's impact on firms' technology innovation and adoption activity. The model 
suggests that monetary policy can exert a significant influence on medium-run TFP dynamics. Overall, the mechanisms emphasized by the model significantly raise the stakes over the conduct of monetary policy, compared to more-conventional settings which treat the evolution of TFP as fully exogenous.

Our approach has relied on the identified effects of R\&D on TFP as a source of discipline on the model's quantitative properties. In addition to R\&D, however, an important channel driving TFP in the model is firms' investment in the adoption of the technologies that result from R\&D efforts. Comprehensive aggregate measures of technology adoption investments are, however, as of yet unavailable. ${ }^{17}$ Collecting such measures would be highly desirable, and would allow further discipline on the model's implications for technology adoption.

Another fruitful line of future research is an analysis of the optimal monetary policy in the presence of endogenous technology innovation and adoption, and how best to approximate by means of simple policy rules. ${ }^{18}$ Incorporating the possibility of recurrent "stagnation traps" (Benigno and Fornaro (2016)) featuring low productivity growth and a binding ZLB constraint within that analysis would be highly desirable as well.

\footnotetext{
${ }^{17}$ Anzoategui et al. (2017) provide some measures of diffusion based on evidence on individual technologies.

${ }^{18}$ Garga and Singh (2016) is a recent example of work in that direction.
} 


\section{Appendix}

\section{A R\&D shocks in a panel of advanced economies}

We next explore whether the effects of R\&D on TFP identified in the U.S. hold more generally in a sample of advanced economies (AEs henceforth). The data consists of a panel of 21 AEs (not including the U.S.) in the post-1980 period (see Appendix F for details on the data). Data on business-sector R\&D expenditure is from the OECD. We select the sample of countries based on the availability of business-sector R\&D data. We specify the following empirical model, analogous to (32):

$$
\left[\begin{array}{c}
y_{i, t} \\
t f p_{i, t} \\
r d_{i, t}
\end{array}\right]=c_{i}+B\left[\begin{array}{c}
y_{i, t-1} \\
t f p_{i, t-1} \\
r d_{i, t-1}
\end{array}\right]+u_{i, t}
$$

The system contains a vector of country fixed effects, $c_{i}$, thus allowing estimation of the country-specific intercept term for each country in the sample. The model, however, imposes the matrix $B$ as well as the variance-covariance matrix of the residuals $u_{i, t}$ to be common across countries. This so-called least-square dummy variable (LSDV) or fixed-effects estimator is commonly used in panel VAR settings with relatively long time series of macroeconomic data-for example, Uribe and Yue (2006), Akinci (2013) or Cerra and Saxena (2008). ${ }^{19}$ We follow the same Choleski approach as in Section 3.2 to identify R\&D shocks.

Figure A.1 shows the impulse responses to an R\&D shock in there different samples. The first row presents results from the United States, the second row from the full panel of AEs, and the third row from the top $5 \mathrm{R} \& \mathrm{D}$ performing economies. We see that a rise in $\mathrm{R} \& \mathrm{D}$ induces a gradual, persistent rise in TFP in all three samples. The TFP increase is statistically significant at the $95 \%$ level. There are, however, some notable differences with the U.S. First and foremost, the TFP response appears to be notably weaker in the panel of advanced economies: R\&D rises about $5.75 \%$ on impact in the AEs (more than in the U.S.), but the overall effect on the level of TFP is about $0.25 \%$, half that in the U.S. Further, the peak effect is reached much later: TFP continues to rise by year 12. By contrast, in the U.S. the TFP response levels out after about eight years. Finally, note that R\&D itself also rises

\footnotetext{
${ }^{19}$ As shown by Nickell (1981), the LSDV estimator is biased due to correlation between the country fixed effects and the lagged dependent variables. This bias, however, is likely to be small in settings like the one above where the time-series dimension is relatively large.
} 
Figure A.1: Response to R\&D shock in a panel of advanced economies
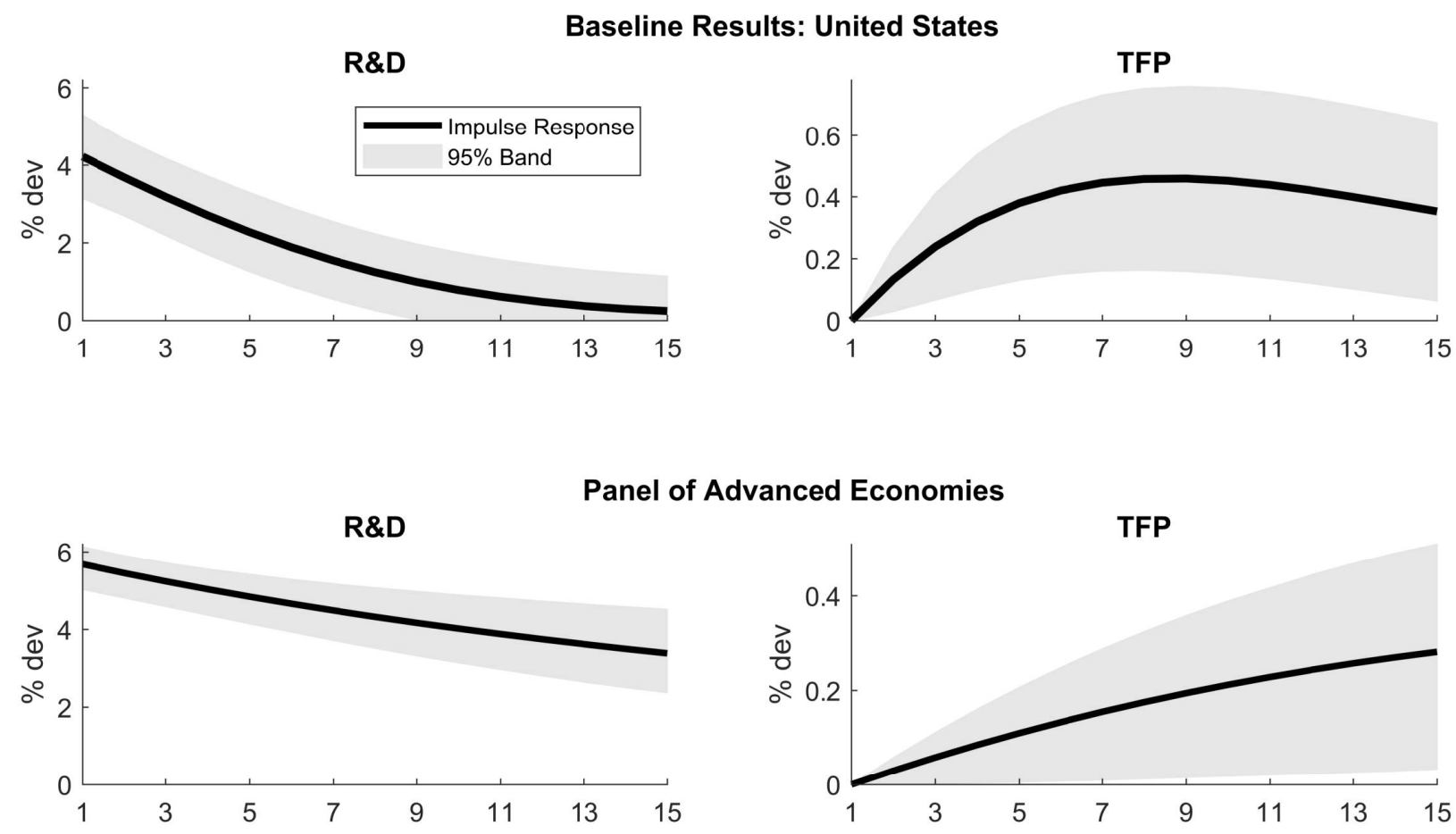

Top 5 R\&D Performing Economies
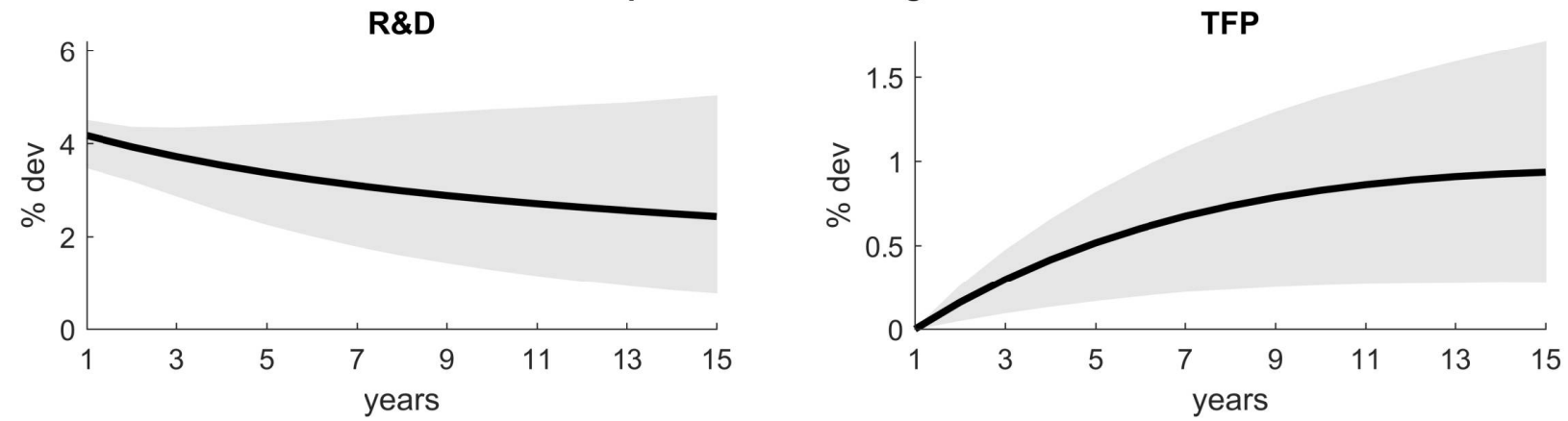

Note: As in Figure 2, the black solid lines show the empirical responses to an identified R\&D shock. The first row presents results from the United States, the second row from the full panel of advanced economies, and the third row from the top 5 R\&D performing economies. The shaded areas indicate $95 \%$ confidence intervals.

much more persistently in the AEs: by year 12 it is still $3.75 \%$ above baseline, while in the U.S. R\&D has returned to baseline by that time. This strengthens our conclusion that R\&D is less powerful in affecting TFP in the AEs, and may also help explain why the TFP rise is more gradual in the AEs than in the U.S., where TFP levels out much sooner.

We have found that there is significant heterogeneity in the effect of an $R \& D$ shock on 
TFP across countries. In particular, the effects on TFP tend to be stronger in countries with higher ratios of private R\&D to GDP. To illustrate this point, the third row of Figure A.1 repeats the same analysis as above, but this time estimation is performed using the top- 5 research economies in our sample as measured by their average R\&D-GDP ratios: Germany, Japan, South Korea, Sweden and Switzerland. We focus on the top 5 for illustration and because they are widely recognized as highly innovative countries, but conclusions hold more generally when we look at reasonable variations in the set of countries, so long as they include countries that are high in the ranking of R\&D-to-GDP. As seen in the Figure, TFP now rises much more than in the full sample of AEs: the peak effect is about $0.9 \%$, much larger than for the full sample, and in fact stronger than for the U.S. in terms of peak TFP response per size of initial rise in $R \& D$. That said, the $R \& D$ movement continues to be much more persistent in this sample of foreign economies than in the U.S.

\section{B Alternative TFP measures}

Throughout our analysis, we have relied upon annual TFP data from the Long-Term Productivity Database published by Bergeaud et al. (2015). This dataset measures TFP in a panel of advanced economies, allowing us to perform the panel analysis in Appendix A. That said, we find similar empirical results when we instead use TFP data published by Fernald (2014).

To explore the impact of using alternative TFP measures, we estimate our small-scale VAR using three different TFP series. When using Fernald TFP, we assume the same recursive ordering as in Equation 32, allowing GDP to impact TFP contemporaneously. When using the utilization-adjusted series, we instead place GDP at the end of the recursive ordering, imposing the assumption that GDP does not impact TFP contemporaneously. We believe this assumption is reasonable, since the utilization adjustment performed by Fernald is designed to account for non-technological factors that vary with the business cycle and also affect measured TFP.

Figure B.1 presents a comparison between the three different estimates of our small-scale VAR. The first row presents our baseline results using BCL, the second row using Fernald TFP, and the third row using Fernald utilization-adjusted TFP. We find that an increase in R\&D induces a persistent rise in TFP, which is statistically significant at the $95 \%$ level for all three measures. The response of Fernald TFP is just under $0.4 \%$ at peak, slightly below our baseline results. When using the utilization-adjusted series, the TFP response is again just under $0.4 \%$ at peak, however, it is interesting to note that the TFP rise is much more gradual and the peak response occurs after 15 years. This is consistent with the view that 
Figure B.1: Comparison between Alternative TFP Measures in the US VAR
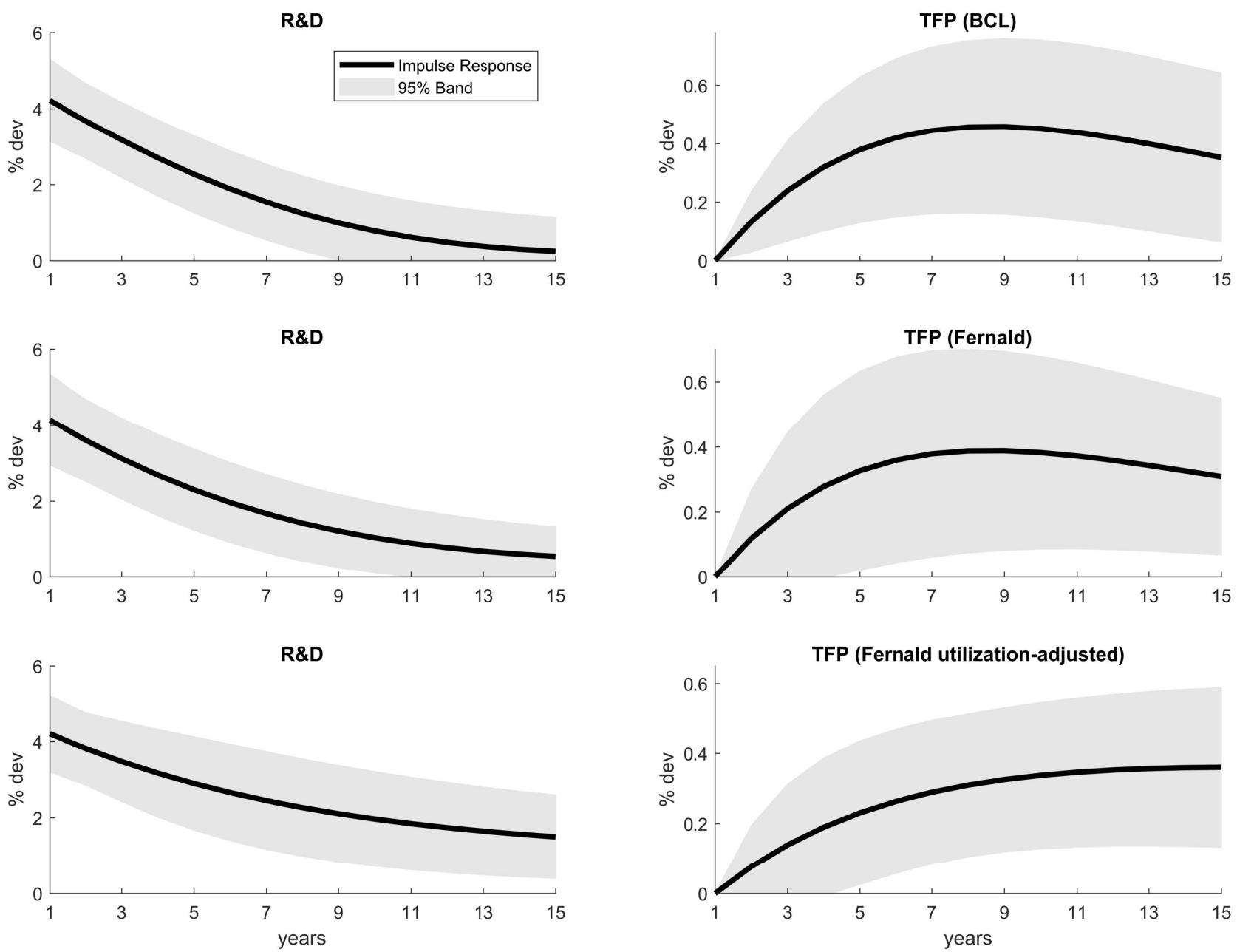

Note: As in Figure 2, the black solid lines show the empirical responses to an identified R\&D shock in the United States and the shaded areas indicate 95\% confidence intervals.

utilization-adjustment removes short term non-technological factors that impact TFP, which may explain the more gradual response.

\section{Monetary Shocks in the United States}

To study the impact of monetary policy on R\&D and TFP, we estimate a monetary VAR following the specification of Christiano et al. (2005). This VAR is estimated using quarterly data, as this is the highest frequency for which $R \& D$ data is available. These results are used in Section 3.3 to asses the model's ability to match the data. 
Figure C.1: Response to a monetary policy shock in the United States
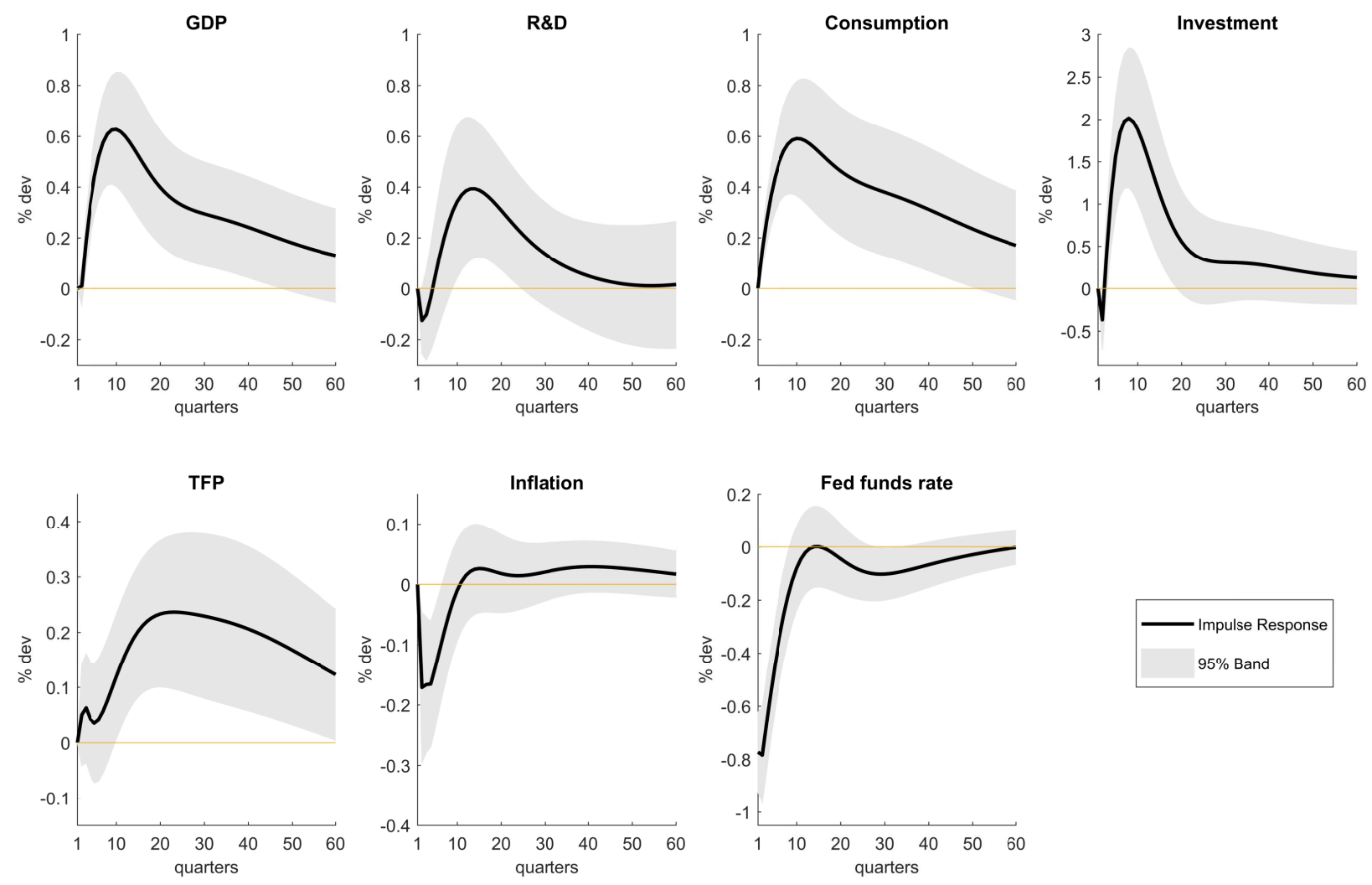

Note: The black solid lines show the empirical responses to an identified monetary policy shock in the United States and the shaded areas indicate $95 \%$ confidence intervals.

Figure C.1 presents the response to a monetary policy shock at a quarterly frequency. To ensure consistency with our model, these impulse responses are averaged in order to obtain the annual series seen in Figure 6.

\section{Complete set of model equilibrium conditions}

In what follows we collect the full set of equations characterizing equilibrium.

$$
\begin{aligned}
A_{t+1} & =\phi\left[\lambda_{t}\left(Z_{t}-A_{t}\right)+A_{t}\right] \\
Z_{t+1} & =\phi Z_{t}+V_{t} \\
V_{t} & =\zeta Z_{t}^{1-\eta} S_{t}^{\eta} \\
J_{t} & =-Q_{t}^{m} M_{t}+\phi \mathbb{E}_{t}\left\{\Lambda_{t, t+1}\left[\lambda_{t} H_{t+1}+\left(1-\lambda_{t}\right) J_{t+1}\right]\right\}
\end{aligned}
$$




$$
\begin{aligned}
& Q_{t}^{m}=1+f_{m}\left(I_{t}^{m} / I_{t-1}^{m}\right)+\frac{I_{t}^{m}}{I_{t-1}^{m}} f_{m}^{\prime}\left(I_{t}^{m} / I_{t-1}^{m}\right)-\mathbb{E}_{t}\left[\Lambda_{t, t+1}\left(\frac{I_{t+1}^{m}}{I_{t}^{m}}\right)^{2} f_{m}^{\prime}\left(I_{t+1}^{m} / I_{t}^{m}\right)\right] \\
& H_{t}=\Pi_{t}+\phi \mathbb{E}_{t}\left(\Lambda_{t, t+1} H_{t+1}\right) \\
& \Pi_{t}=\frac{1}{\vartheta} \frac{1}{\mathcal{M}_{t}} \frac{Y_{t}}{A_{t}} \\
& \mathbb{E}_{t}\left(\Lambda_{t, t+1} J_{t+1}\right) \zeta\left(\frac{Z_{t}}{S_{t}}\right)^{1-\eta}=\left(1+\Delta_{t}^{s}\right)\left\{1+f_{s}^{\prime}\left(S_{t} / S_{t-1}\right) \frac{S_{t}}{S_{t-1}}\right. \\
& \left.+f_{s}\left(S_{t} / S_{t-1}\right)-\mathbb{E}_{t}\left[\Lambda_{t, t+1} f_{s}^{\prime}\left(S_{t+1} / S_{t}\right)\left(\frac{S_{t+1}}{S_{t}}\right)^{2}\right]\right\} \\
& Q_{t}^{m} M_{t}^{1-\rho_{\lambda}}=\rho_{\lambda} \kappa_{\lambda} \phi\left(S_{t} / A_{t}\right)^{\nu} \mathbb{E}_{t}\left[\Lambda_{t, t+1}\left(H_{t+1}-J_{t+1}\right)\right] \\
& \lambda_{t}=\kappa_{\lambda}\left(S_{t} / A_{t}\right)^{\nu} M_{t}^{\rho_{\lambda}} \\
& Y_{t}=A_{t}^{\frac{1}{\vartheta-1}} K_{t}^{\alpha} L_{t}^{1-\alpha} \\
& Y_{t}=C_{t}+\left[1+f_{i}\left(I_{t} / I_{t-1}\right)\right] I_{t}+\left[1+f_{m}\left(I_{t}^{m} / I_{t-1}^{m}\right)\right] I_{t}^{m}+\left[1+f_{s}\left(S_{t} / S_{t-1}\right)\right] S_{t} \\
& \Lambda_{t, t+1}=\frac{\beta U_{C, t+1}}{U_{C, t}} \\
& U_{C, t}=\frac{1}{C_{t}-h C_{t-1}}-\beta h \mathbb{E}_{t}\left(\frac{1}{C_{t+1}-h C_{t}}\right) \\
& w_{t}=\frac{1}{\mathcal{M}_{t}} \frac{\vartheta-1}{\vartheta}(1-\alpha) \frac{Y_{t}}{L_{t}} \\
& K_{t+1}=(1-\delta) K_{t}+I_{t} \\
& Q_{t}=1+f_{i}\left(I_{t} / I_{t-1}\right)+\frac{I_{t}}{I_{t-1}} f_{i}^{\prime}\left(I_{t} / I_{t-1}\right)-\mathbb{E}_{t}\left[\Lambda_{t+1}\left(\frac{I_{t+1}}{I_{t}}\right)^{2} f_{i}^{\prime}\left(I_{t+1} / I_{t}\right)\right] \\
& 1=\mathbb{E}_{t}\left(\Lambda_{t, t+1} \frac{\frac{\vartheta-1}{\vartheta} \frac{1}{\mathcal{M}_{t+1}} \alpha \frac{Y_{t+1}}{K_{t+1}}+(1-\delta) Q_{t+1}}{Q_{t}}\right) \\
& I_{t}^{m}=\left(Z_{t}-A_{t}\right) M_{t} \\
& \pi_{t}^{1-\omega}=\theta\left(\pi_{t-1}^{\iota_{p}} \bar{\pi}^{1-\iota_{p}}\right)^{1-\omega}+(1-\theta)\left(\pi_{t}^{*}\right)^{1-\omega} \\
& \pi_{t}^{*}=\frac{\omega}{\omega-1} \frac{x_{1, t}}{x_{2, t}} \pi_{t} \\
& x_{1, t}=U_{C D, t} \mathcal{M}_{t}^{-1} Y_{D, t}+\theta \beta\left(\pi_{t}^{\iota_{p}} \bar{\pi}^{1-\iota_{p}}\right)^{-\omega} \mathbb{E}_{t}\left(x_{1, t+1} \pi_{t+1}^{\omega}\right) \\
& x_{2, t}=U_{C D, t} Y_{D, t}+\beta \theta\left(\pi_{t}^{\iota p} \bar{\pi}^{1-\iota_{p}}\right)^{1-\omega} \mathbb{E}_{t}\left(x_{2, t+1} \pi_{t+1}^{\omega-1}\right) \\
& 1=\mathbb{E}_{t}\left[\Lambda_{t, t+1} \frac{R_{t}}{\pi_{t+1}}\right] \\
& R_{t}=\frac{\bar{g}}{\beta} \bar{\pi}\left(\frac{\pi_{t}}{\bar{\pi}}\right)^{\gamma_{\pi}}\left(\frac{Y_{t} / A_{t}}{Y_{t}^{p o t} / A_{t}^{p o t}}\right)^{\gamma_{y}} \Delta_{t}^{r}
\end{aligned}
$$




$$
\begin{aligned}
w_{t}^{1-\omega_{l}} & =\left(1-\theta_{w}\right)\left(w_{t}^{*}\right)^{1-\omega_{l}}+\theta_{w}\left[\pi_{t}^{-1} w_{t-1} \bar{g}\left(\pi_{t-1}^{\iota_{w}} \bar{\pi}^{1-\iota_{w}}\right)\right]^{1-\omega_{l}} \\
w_{t}^{*} & =\mathcal{M}_{w} \frac{x_{1 w, t}}{x_{2 w, t}} \\
x_{1 w, t} & =L_{t}^{*} U_{C, t} M R S_{t}+\beta \theta_{w} \mathbb{E}_{t}\left(x_{2 w, t+1}\right) \\
x_{2 w, t} & =L_{t}^{*} U_{C, t}+\beta \theta_{w} \bar{g}\left(\pi_{t}^{\iota_{w}} \bar{\pi}^{1-\iota_{w}}\right) \mathbb{E}_{t}\left(\pi_{t+1}^{-1} x_{2 w, t+1}\right) \\
L_{t}^{*} & =\left(\frac{w_{t}^{*}}{w_{t}}\right)^{-\omega_{l}} L_{t} \\
M R S_{t} & =\frac{\chi\left(L_{t}^{*}\right)^{\epsilon}}{U_{C, t}}
\end{aligned}
$$

Equations (D.1)-(D.31) can be solved for the endogenous variables $A_{t+1}, Z_{t+1}, V_{t}, J_{t}, Q_{t}^{m}, H_{t}, \Pi_{t}$, $S_{t}, M_{t}, \lambda_{t}, Y_{t}, C_{t}, \Lambda_{t, t+1}, w_{t}, K_{t+1}, Q_{t}, I_{t}, I_{t}^{m}, \pi_{t}, \pi_{t}^{*}, x_{1, t}, x_{2, t}, R_{t}, w_{t}, w_{t}^{*}, x_{1 w, t}, x_{2 w, t}, L_{t}^{*}, M R S_{t}, U_{C, t}, \mathcal{M}_{t}$. The potential economy is characterized by the same equations above, setting $\theta=\theta_{w}=0$.

\section{E Additional model results}

\section{E.1 Taylor rule including technology in the output gap}

Figure E.1 compares the effects of a contractionary monetary shock under our baseline Taylor rule to an alternative that responds to $Y_{t} / Y_{t}^{\text {pot }}$ (rather than to $y_{t} / y_{t}^{p o t}$ ). Note that under the alternative rule, TFP and output eventually revert back to baseline: under the alternative rule, the policymaker seeks to close a measure of the output gap that includes endogenous technology $A_{t}$. Note also the significant overshooting of inflation, which turns positive for several years before reverting back to zero. These results are broadly consistent with those found by Erceg and Levin (2014), and result from the presence of a slow-moving state variable in the Taylor rule (technology in our case, and labor force participation in the case of Erceg and Levin (2014)).

\section{E.2 Efficient allocation and alternative Taylor rules}

Here we compare the model behavior under alternative Taylor rules which target the efficient allocation (featuring socially optimal innovation), rather than potential. We abstract from a number of model features to keep the analysis tractable. In particular, we abstract from capital accumulation (and set $\alpha=0$ ), habits, adjustment costs, and nominal wage rigidities, and indexation to past inflation. We also set the $R \& D$ impact on adoption rates to zero: $\nu=0$. 
Figure E.1: Monetary shock, baseline and alternative Taylor rule
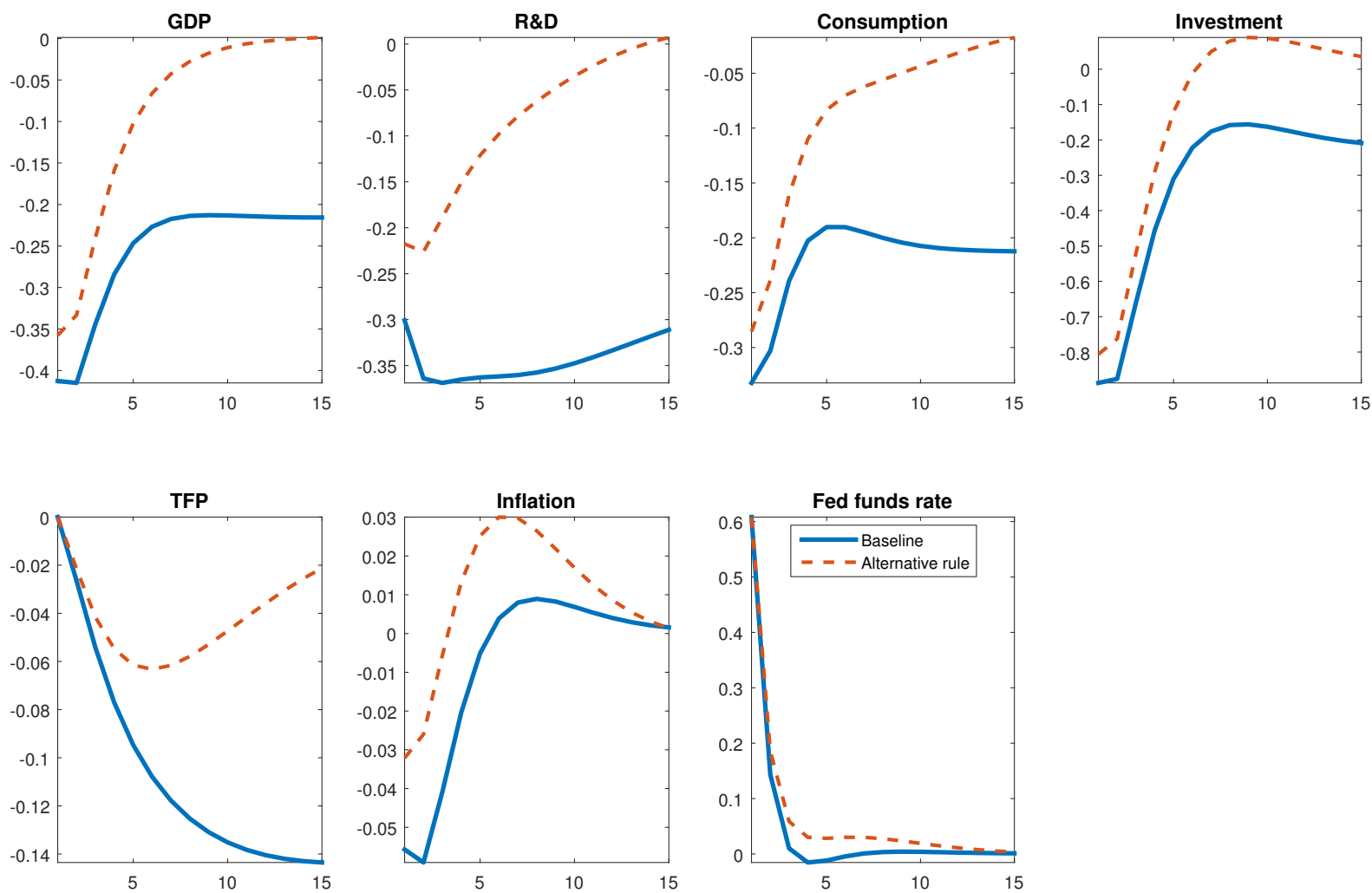

Note: The alternative Taylor rule responds to $Y_{t} / Y_{t}^{\text {pot }}$.

We begin by characterize the socially optimal allocation. The planner maximizes $\sum_{t=1}^{\infty} \beta^{t} U\left(C_{t}, L_{t}\right)$ subject to the constraints

$$
\begin{aligned}
A_{t+1} & =\lambda_{t} \phi\left(Z_{t}-A_{t}\right)+\phi A_{t} \\
\lambda_{t} & =\kappa_{\lambda} M_{t}^{\rho_{\lambda}} \\
Z_{t+1} & =\phi Z_{t}+\zeta_{t} Z_{t}^{1-\eta} S_{t}^{\eta} \\
A_{t}^{\frac{1}{\vartheta-1}} L_{t} & =C_{t}+S_{t}+M_{t}\left(Z_{t}-A_{t}\right)
\end{aligned}
$$

for all $t$. We assume that the productivity of $\mathrm{R} \& \mathrm{D}, \zeta_{t}$, follows an exogenous first-order autoregressive process, playing a role akin to the innovation wedge in the main text.

Eliminate $\lambda_{t}$ and write the Lagrangian 


$$
\begin{array}{r}
\mathcal{L}=\mathbb{E}_{0} \sum_{t=1}^{\infty} \beta^{t}\left\{U\left(C_{t}, L_{t}\right)+\gamma_{A t} \gamma_{C t}\left[\kappa_{\lambda} M_{t}^{\rho_{\lambda}} \phi\left(Z_{t}-A_{t}\right)+\phi A_{t}-A_{t+1}\right]\right. \\
\left.+\gamma_{Z t} \gamma_{C t}\left[\phi Z_{t}+\zeta_{t} Z_{t}^{1-\eta} S_{t}^{\eta}-Z_{t+1}\right]+\gamma_{C t}\left[A_{t}^{\frac{1}{\vartheta-1}} L_{t}-C_{t}-S_{t}-M_{t}\left(Z_{t}-A_{t}\right)\right]\right\}
\end{array}
$$

where $\gamma_{A t} \gamma_{C t}, \gamma_{Z t} \gamma_{C t}$ and $\gamma_{C t}$ are the multipliers on (E.1), (E.3), and (E.4) respectively. Taking first order conditions of the problem above and collecting the constraints yields the following system:

$$
\begin{aligned}
A_{t+1} & =\lambda_{t} \phi\left(Z_{t}-A_{t}\right)+\phi A_{t} \\
\lambda_{t} & =\kappa_{\lambda} M_{t}^{\rho_{\lambda}} \\
Z_{t+1} & =\phi Z_{t}+\zeta_{t} Z_{t}^{1-\eta} S_{t}^{\eta} \\
A_{t}^{\frac{1}{\vartheta-1}} L_{t} & =C_{t}+S_{t}+M_{t}\left(Z_{t}-A_{t}\right) \\
\chi L_{t}^{\epsilon} C_{t} & =A_{t}^{\frac{1}{\vartheta-1}} \\
1 & =\gamma_{Z t} \eta \zeta_{t}\left(\frac{S_{t}}{Z_{t}}\right)^{\eta-1} \\
1 & =\gamma_{A t} \kappa_{\lambda} \rho_{\lambda} M_{t}^{\rho_{\lambda}-1} \phi \\
\gamma_{Z t} & =\mathbb{E}_{t}\left\{\frac{\beta C_{t+1}^{-1}}{C_{t}^{-1}}\left\{\gamma_{A t+1} \lambda_{t+1} \phi+\gamma_{Z t+1}\left[\phi+\zeta_{t+1}(1-\eta)\left(\frac{S_{t+1}}{Z_{t+1}}\right)^{\eta}\right]-M_{t+1}\right\}\right\} \\
\gamma_{A t} & =\mathbb{E}_{t}\left\{\frac{\beta C_{t+1}^{-1}}{C_{t}^{-1}}\left\{\gamma_{A t+1} \phi\left(1-\lambda_{t+1}\right)+\frac{1}{\vartheta-1} A_{t+1}^{\frac{1}{\vartheta-1}-1} L_{t+1}+M_{t+1}\right\}\right\}
\end{aligned}
$$

The above constitute 9 equations in $A_{t+1}, \lambda_{t}, Z_{t+1}, C_{t}, L_{t}, S_{t}, M_{t}, \gamma_{Z t}, \gamma_{A t}$, characterizing the efficient allocation.

We perform the following experiments. We document the responses of the efficient and potential economies, as well as the responses of the "actual" economy under two variants of the Taylor rule: one which responds to deviations of output from potential $\left(Y_{t} / Y_{t}^{\text {pot }}\right)$ and another that responds to deviations of output from efficient output, as characterized by the above system. In all cases, we assume constant subsidies to labor, $R \& D$, and adoption along the balanced growth path in the actual and flex-price (or potential) economies, such that labor supply, the adoption rate and the TFP growth rate are equal to those in the efficient economy (with values given by the targets described in 3.1). Given these subsidies, all three 
Figure E.2: Monetary shock, efficient and potential economy and alternative Taylor rules
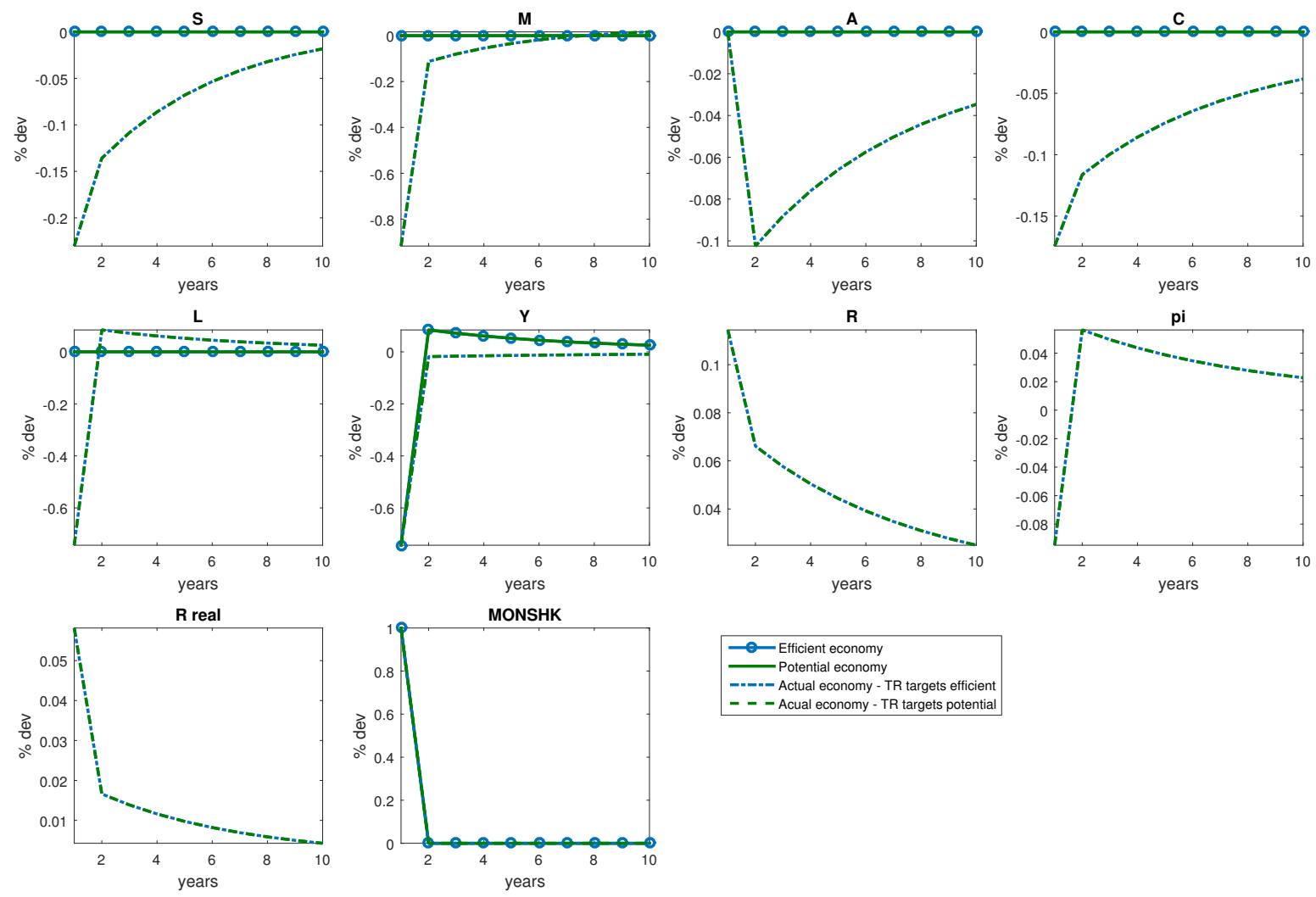

Note: Effects of monetary policy shock in the efficient (blue circled line) and potential (green solid line) economies, as well as in the actual economy under two variants of the Taylor rule: one that targets efficient output (blue dash-dotted line) and another that targets potential (green dashed line).

economies have identical balanced growth paths.

Figure E.2 shows the effects of a monetary policy shock in the actual economy under the two variants of the Taylor rule. As the Figure makes clear, the behavior of the actual economy is the same under the two rules. The reason is that neither the potential nor the efficient economies are affected by the monetary shock. The same is true for the frequently used "liquidity preference" shock (see Fisher (2015)), as the latter has no allocative effects absent nominal rigidities.

There are, however, other types of exogenous disturbances under which the economy's behavior will differ depending on which Taylor rule is followed by the monetary authority. To illustrate this point, we explore the effects of a one percent disturbance to the R\&D efficiency, $\zeta_{t}$, with persistence set to 0.5. As seen in Figure E.3, the evolution of the efficient (blue circled line) and the potential (green solid) economies following a positive innovation to $\zeta_{t}$ is quite different. From the first two panels, R\&D increases more in the efficient economy than in 
the potential economy, and adoption expenditure (and therefore the adoption rate) falls by less - resulting in a substantially larger medium-run rise in TFP. Note also that consumption falls by more in the first few years (reflecting a greater desire of the planner to reallocate expenditure to innovation) in the efficient economy, and labor rises by more throughout.

Turning to the actual economy, we find that the Taylor rule targeting efficient output is quite effective in inducing all variables to track their respective paths in the efficient economy. A similar observation applies to the case in which the Taylor rule targets potential output. As a result, the behavior of the actual economy is quite different across the two rules, and mirrors the differences between the efficient and potential economies. Note also that the effects of the shock on inflation and the nominal interest rate are also quite different, with inflation rising substantially more under the Taylor rule that targets efficient output. This is suggestive of a tradeoff for the monetary authority, as tracking the efficient economy entails greater costs in terms of nominal instability. 
Figure E.3: R\&D efficiency shock, efficient and potential economy and alternative Taylor rules
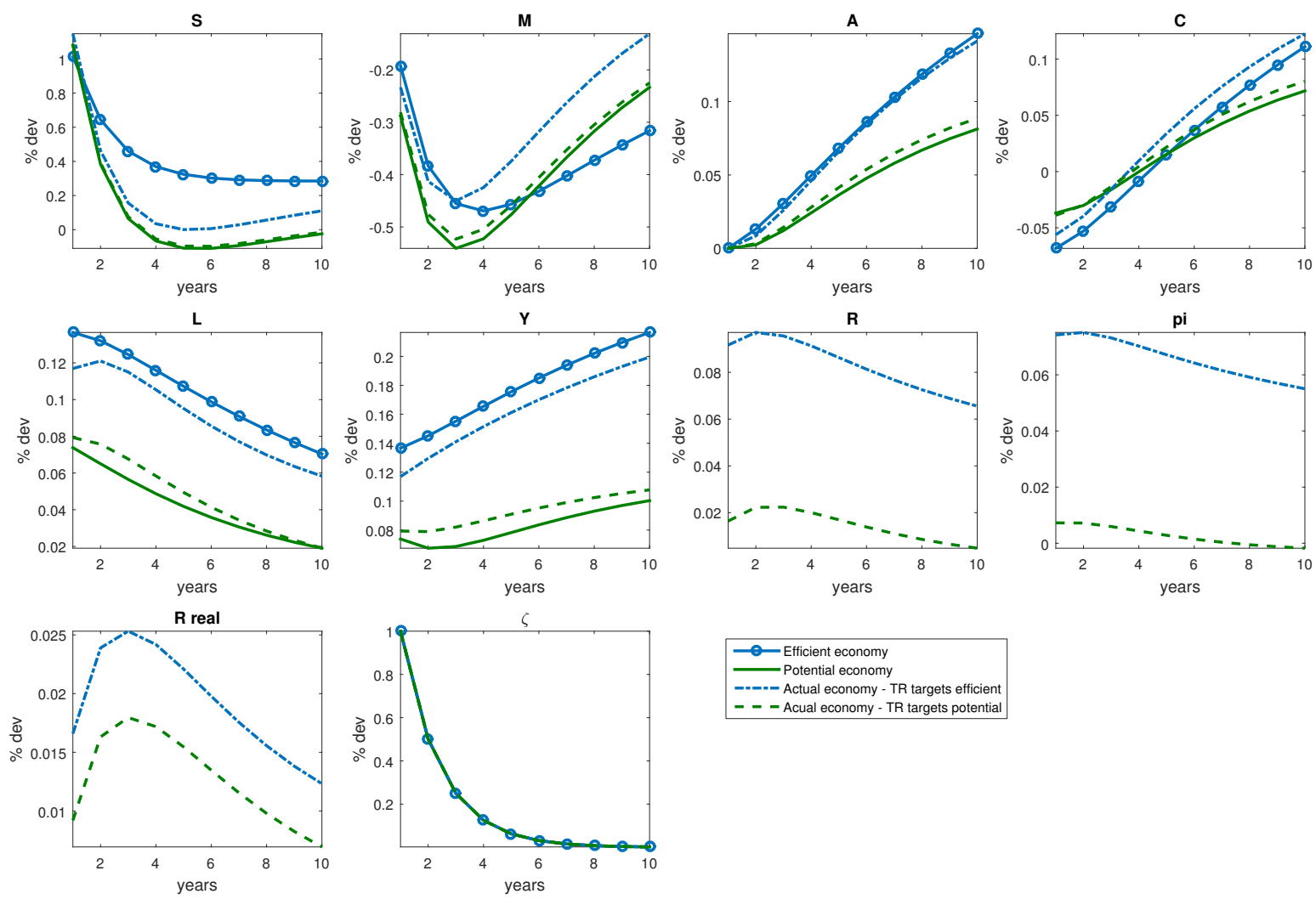

Note: Effects of shock to R\&D efficiency $\zeta_{t}$ in the efficient (blue circled line) and potential (green solid line) economies, as well as in the actual economy under two variants of the Taylor rule: one that targets efficient output (blue dash-dotted line) and another that targets potential (green dashed line).

\section{F Data}

We estimate the small and large-scale VARs at the annual frequency, in order to take advantage of the most reliable R\&D data for the United States, which is published by the National Science Foundation. We estimate the monetary VAR using quarterly data, following the example of Christiano et al. (2005).

\section{F.1 Annual Data}

The most reliable R\&D data for the United States comes from the National Science Foundation, which currently surveys approximately 45,000 companies on an annual basis. Com- 
panies are legally required to respond to the survey. ${ }^{20}$ We use real business sector R\&D, ${ }^{21}$ performed in the domestic United States by companies with five or more employees, publicly or privately held. This includes labor costs, which in recent years constitute approximately two thirds of R\&D costs. Data comes from the NSF's Science and Engineering Indicators 2016, Appendix Table 4-2, available online.

TFP comes from The Long-Term Productivity database published by Bergeaud et al. (2015). These authors compute TFP as the Solow residual from a Cobb-Douglas production function with constant returns to scale and with capital stock and hours worked as input. We select this measure of TFP to ensure comparability across countries, allowing us to estimate the impact of R\&D shocks in a panel of advanced economies.

Real GDP comes from the National Income and Product Accounts of the United States. Investment is defined as real gross private domestic investment minus real business R\&D expenditure, in order to ensure consistency with the model. The federal funds rate is measured as the $\mathrm{Wu}$ and Xia (2016) Shadow Rate. Inflation is defined as the log difference of the GDP deflator. Finally, consumption is defined as real personal consumption expenditures.

\section{F.2 Quarterly Data}

We use the newly released quarterly $R \& D$ data published by the BEA in the National Income and Product Accounts. This data is used by Bianchi et al. (2014) to estimate a quarterly model of endogenous productivity growth. While this is the only quarterly R\&D series for United States, it is not without limitations. Most importantly, the BEA R\&D measure omits software R\&D, which in recent years has been about $20 \%$ of total business R\&D. Data comes from NIPA Table 5.3.3, which presents real private fixed investment by type.

We use quarterly utilization-adjusted TFP published by Fernald (2014), as the LongTerm Productivity database is only available at the annual frequency. For the remaining macroeconomic variables included in the monetary VAR, we use the quarterly version of all series described in Appendix F.1.

\footnotetext{
20 "Your Response is Required by Law" is printed on the first page of the Business R\&D and Innovation Survey. The survey further clarifies that "Title 13, United States Code, requires businesses and other organizations that receive this questionnaire to answer the questions and return the report to the Census Bureau."

${ }^{21}$ The NSF defines R\&D as "planned, creative work aimed at discovering new knowledge or developing new or significantly improved goods and services." This includes basic research aimed at acquiring new knowledge, applied research that solves specific problems, and development that produces new or significantly improved goods, services, or processes. It does not include routine product testing, market research, or exploration for natural resources.
} 


\section{F.3 Panel Data}

Our panel consists of annual data for 22 advanced economies. We include the same countries as Coe et al. (2009), with just two exceptions due to data availability. ${ }^{22}$ Table F.1 contains a complete list of the countries and years included in our panel.

$R \& D$ is measured as R\&D expenditure performed by business enterprise in constant US dollars. Data comes from the OECD Research and Development Statistics. For the United States, this series is equivalent to real business sector $R \& D$ expenditure as published by the NSF.

Our primary source of TFP data is the Long-Term Productivity database published by Bergeaud et al. (2015). This data is designed for cross country comparisons and is available for 17 advanced economies including the United States. For the five remaining countries in our panel, we use TFP data from the Total Economy Database produced by The Conference Board. These series are augmented with Information and Communications Technology (ICT) and Labor Quality. These series are used for Austria, Ireland, Israel, New Zealand, and South Korea.

Gross Domestic Product is measured in constant US dollars, as published in the Total Economy Database produced by The Conference Board.

\footnotetext{
${ }^{22}$ Greece and Iceland are both excluded due to a lack of R\&D data.
} 
Table F.1: Panel Dataset

\begin{tabular}{lc}
\hline \hline Country & Sample \\
\hline Australia & $1981-2011$ \\
Austria & $1989-2013$ \\
Belgium & $1981-2013$ \\
Canada & $1981-2013$ \\
Denmark & $1981-2013$ \\
Finland & $1981-2013$ \\
France & $1981-2013$ \\
Germany & $1981-2013$ \\
Ireland & $1989-2012$ \\
Israel & $1991-2013$ \\
Italy & $1981-2013$ \\
Japan & $1981-2013$ \\
Netherlands & $1981-2013$ \\
New Zealand & $1989-2011$ \\
Norway & $1981-2013$ \\
Portugal & $1982-2013$ \\
South Korea & $1995-2013$ \\
Spain & $1981-2013$ \\
Sweden & $1981-2013$ \\
Switzerland & $1981-2012$ \\
United Kingdom & $1981-2013$ \\
United States & $1953-2016$ \\
\hline \hline
\end{tabular}




\section{References}

Akinci, Ozge, "Global financial conditions, country spreads and macroeconomic fluctuations in emerging countries," Journal of International Economics, 2013. A

Anzoategui, Diego, Diego Comin, Mark Gertler, and Joseba Martinez, "Endogenous Technology Adoption and R\&D as Sources of Business Cycle Persistence," 2017. 3, $1,2.10,3.1,3.2,17$

Benigno, Gianluca and Luca Fornaro, "Stagnation traps," 2016. 3, 5

Bergeaud, Antonin, Gilbert Cette, and Remy Lecat, "Long-run per-capita gross domestic product in France and the advanced countries: the role of productivity and labour," Economie 83 Statistique, 2015. B, F.1, F.3

Bianchi, Francesco, Howard Kung, and Gonzalo Morales, "Growth, Slowdowns, and Recoveries," 2014. 3, 1, 2.10, F.2

Caballero, Ricardo J. and Adam B. Jaffe, "How High are the Giants' Shoulders: An Empirical Assessment of Knowledge Spillovers and Creative Destruction in a Model of Economic Growth," in "NBER Macroeconomics Annual 1993, Volume 8," MIT press, 1993, pp. $15-86.3 .1$

Cerra, Valerie and Sweta Chaman Saxena, "Growth Dynamics: the Myth of Economic Recovery," American Economic Review, 2008, 98 (1), 439-457. A

Christiano, Lawrence J., Martin Eichenbaum, and Charles L. Evans, "Nominal Rigidities and the Dynamic Effects of a Shock to Monetary Policy," Journal of Political Economy, 2005, 113 (1), 1-45. 3.1, 11, C, F

_ , _ , and Mathias Trabandt, "Understanding the Great Recession," American Economic Journal: Macroeconomics, 2015, 7 (1), 110-67. 3.3

Coe, David T., Elhanan Helpman, and Alexander W. Hoffmaister, "International R\&D Spillovers and Institutions," European Economic Review, 2009, 53 (7), 723-741. F.3

Comin, Diego and Mark Gertler, "Medium-Term Business Cycles," American Economic Review, 2006, pp. 523-551. 3, 1, 2.1, 2.3, 2.10, 3.1, 3.2

Del Negro, Marco, Marc P. Giannoni, and Frank Schorfheide, "Inflation in the Great Recession and New Keynesian Models," American Economic Journal: Macroeconomics, 2015, 7 (1), 168-196. 3.1 
Erceg, Christopher J. and Andrew T. Levin, "Labor Force Participation and Monetary Policy in the Wake of the Great Recession," Journal of Money, Credit and Banking, 2014, 46 (S2), 3-49. E.1

_, Dale W. Henderson, and Andrew T. Levin, "Optimal monetary policy with staggered wage and price contracts," Journal of Monetary Economics, 2000, 46 (2), 281-313. $2.7,2.8$

Fernald, John, "Productivity and Potential Output Before, During, and After the Great Recession," in "NBER Macroeconomics Annual 2014, Volume 29," University of Chicago Press, 2014. 3.2, 3.3, B, F.2

Fisher, Jonas D.M., "On the Structural Interpretation of the Smets-Wouters Risk Premium Shock," Journal of Money, Credit and Banking, 2015, 47 (2-3), 511-516. E.2

Garga, Vaishali and Sanjay R. Singh, "Output Hysteresis and Optimal Monetary Policy," 2016. 18

Gilchrist, Simon and Egon Zakrajšek, "Credit Spreads and Business Cycle Fluctuations," American Economic Review, 2012, 102 (4), 1692-1720. 4

Griffith, Rachel, Stephen Redding, and John Van Reenen, "Mapping the two faces of R\&D: Productivity growth in a panel of OECD industries," Review of Economics and Statistics, 2004, 86 (4), 883-895. 6, 2.10

Guerron-Quintana, Pablo and Ryo Jinnai, "Liquidity, Trends, and the Great Recession," 2014. 3

Holston, Kathryn, Thomas Laubach, and John C. Williams, "Measuring the natural rate of interest: International trends and determinants," Journal of International Economics, 2017. 3.1

Justiniano, Alejandro, Giorgio E. Primiceri, and Andrea Tambalotti, "Investment shocks and business cycles," Journal of Monetary Economics, 2010, 57 (2), 132-145. 3.1

Kung, Howard and Lukas Schmid, "Innovation, Growth, and Asset Prices," The Journal of Finance, 2015, 70 (3), 1001-1037. 3, 9

Nickell, Stephen, "Biases in dynamic models with fixed effects," Econometrica, 1981, pp. 1417-1426. 19 
Primiceri, Giorgio E., Ernst Schaumburg, and Andrea Tambalotti, "Intertemporal disturbances," 2006. 3.1

Queralto, Albert, "A Quantitative Model of Slow Recoveries from Financial Crises," International Finance Discussion Papers, Board of Governors, 2013. 3, 4

Reifschneider, David, "Gauging the Ability of the FOMC to Respond to Future Recessions," 2016. Finance and Economics Discussion Series 2016-068. Washington: Board of Governors of the Federal Reserve System, http://dx.doi .org/10.17016/FEDS . 2016.068. $3.1,4.1$

Romer, Paul, "Endogenous Technological Change," Journal of Political Economy, 1990, pp. S71-S102. 1, 2.1, 2.2, 2.10

Smets, Frank and Rafael Wouters, "Shocks and Frictions in US Business Cycles: A Bayesian DSGE Approach," American Economic Review, 2007, 97 (3), 586-606. 3.1

Taylor, John B., Monetary Policy Rules, University of Chicago Press, 1999. 3.1

Uribe, Martín and Vivian Z. Yue, "Country Spreads and Emerging Countries: Who drives Whom?," Journal of International Economics, 2006, 69 (1), 6-36. A

Wu, Jing Cynthia and Fan Dora Xia, "Measuring the Macroeconomic Impact of Monetary Policy at the Zero Lower Bound," Journal of Money, Credit and Banking, 2016, 48 (2-3), 253-291. 3.3, F.1

Yellen, Janet L., "Current Conditions and the Outlook for the U.S. Economy," 2016. The World Affairs Council of Philadelphia, 6 June 2016, Speech. 2

_, "The Federal Reserve's Monetary Policy Toolkit: Past, Present, and Future," 2016. Speech delivered at "Designing Resilient Monetary Policy Frameworks for the Future," a symposium sponsored by the Federal Reserve Bank of Kansas City, held in Jackson Hole, Wyoming, August 2016. 4.1 